\title{
Wave Front Steepness and Influence on Horizontal Deck Impact Loads
}

\author{
Carl Trygve Stansberg \\ Ctstansberg Marinteknikk, Julianus Holms veg 10, NO-7041 Trondheim, Norway; \\ ctstansberg.marinteknikk@gmail.com; Tel.: +47-93268363
}

Received: 15 January 2020; Accepted: 24 April 2020; Published: 29 April 2020

\begin{abstract}
In design storm sea states, wave-in-deck forces need to be analysed for fixed and floating offshore platforms. Due to the complex physics of wave impact phenomena, numerical analyses should be complemented by model test data. With a large statistical variability, such experiments usually involve running many 3-h storm realisations. Efforts are being done to establish efficient procedures and still obtain improved statistical accuracy, by means of an initial simplified screening based on parameters derived from the incident wave record only. Here, we investigate the vertical rise velocity of the incident wave elevation at a fixed point in space, which indirectly measures both the local slope and the near-surface orbital velocity. A derived simple deck slamming model is also suggested, to support the check of the physical basis of the approach. Correlation against data from a GBS wave-in-deck model test is used for checking this model. The results show that, although there is a significant random scatter in the measured impact forces, especially in the local slamming forces but also in the global forces, there is a correlation to the rise velocity. Comparisons to the simple load model also show promising results when seen on background of the complex physics and random scatter of the impact problem.
\end{abstract}

Keywords: ocean waves; wave steepness; platform deck; wave impact; slamming; model test; critical events; data reduction

\section{Introduction}

Wave-in-deck loads on fixed and floating platform decks in stormy weather has become an increasingly important issue for the offshore industry during the last decades. Ideally, platforms are intentionally designed to avoid negative air-gap, but in practice it is difficult to avoid in design storm sea states. Therefore, at least for steep design sea states such as those indicated in Figure 1 it is important to have proper knowledge of such loads, and to include it in structural design. The need for this is further emphasised by actual events such as the COSL Innovator accident December 2015 in the North Sea [1]. Recently, updated and new industry guidelines have been established, such as DNV GL's new guidelines OTG-13 [2] and OTG-14 [3] for mobile units. Both the air-gap and load problems have been addressed at least since the 1990s [4-6], initially mostly for fixed platforms. It has for quite some time also been well reflected in general industry recommendations, exemplified by DNVGL's RP-C205 which was recently updated [7] while it was originally issued in 2007.

As one can read from these recommendations, standard industry tools are not fully capable of predicting such strongly nonlinear random wave-structure phenomena to a satisfactory level, and hydrodynamic model testing is generally needed (although some simplified formulations are given in case test data are not available). A wave-in-deck model test study on a gravity-based structure (GBS) in extreme random waves is presented in [8], from which an illustrative example is shown in Figure 2. Here, typical time series samples of the wave elevation and resulting horizontal and vertical impact loads are presented, for both global and local slamming forces. Furthermore, three different 
wave-in-deck experiments have recently been presented in [9-11] where also the corresponding wave characteristics as well as detailed complexities in the impact are addressed.

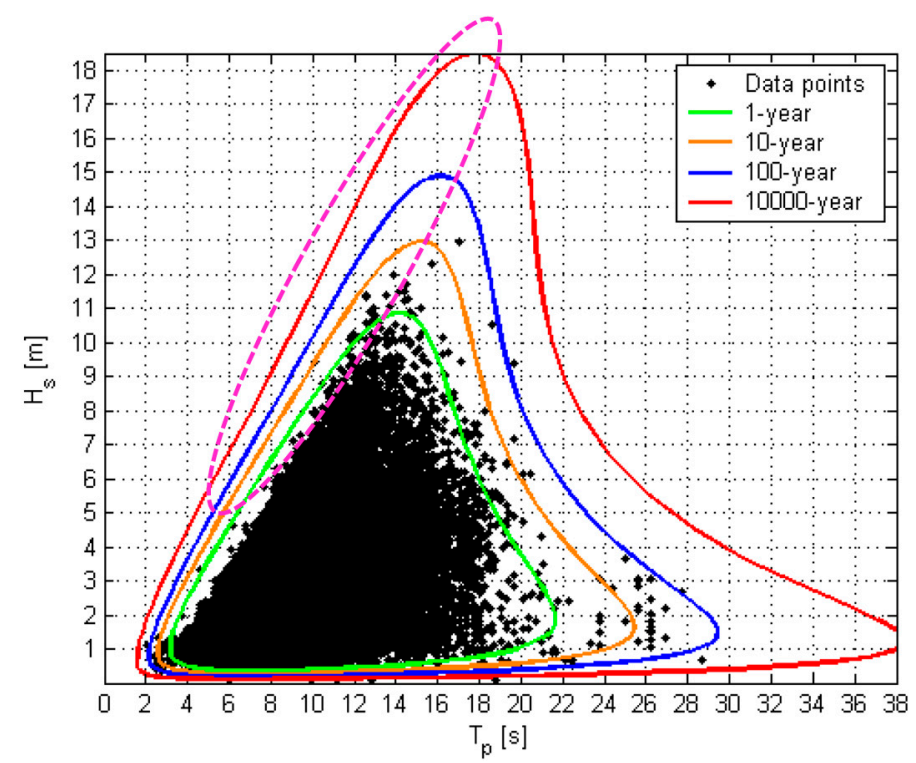

Figure 1. Environmental contour lines for the northern North Sea, including an indication of critical area for wave impact. Based on figure in [8].

In addition, sophisticated numerical tools such as CFD and similar are in constant development and are increasingly in use for this problem (in which model tests do play an important role for validation). Some examples can be found in [12-15]. At present, these studies are still often made on a research basis. Some of them deal with the accurate simulation of the kinematics in steep and breaking waves, which is clearly relevant for the wave impact problem.

A full design analysis of an offshore structure in extreme environmental conditions must include, in addition to wave loads on both the substructure and superstructure, the dynamic responses as well as loads and responses due to wind and current. Various types of component analysis must be combined, such as described in the system approach in [16], and interaction effects between various environmental inputs may in some cases be non-negligible for the resulting response [17]. In the present study, however, we consider pure wave-in-deck loads only, and possible consequences for the structural integrity etc. are left for subsequent analysis.

Given the rare occurrence of the critical wave impact phenomena, both approaches-experimental and numerical — can be quite time-consuming for a proper statistical robustness to be obtained. Thereby, many recent model test campaigns do include multiple 3-h realisations (seed numbers), with typically up to 20 seeds, and sometimes even more (see, e.g., [18,19]). However, e.g., in the case of wave slamming on columns, it is found in [18] that even with almost 100 realisations there is a statistical uncertainty to be taken into account, at least when using the frequently applied contour method reflected in Figure 1.

There have been several efforts to reduce the need to run many full 3-h records [8,20-22]. The idea is to identify and isolate critical random wave events, based on criteria for certain wave parameters and their possible connection with the actual wave-structure interaction, and use only them in the tests or simulations. For this, we need to identify and qualify proper wave parameters/indicators and criteria. This is indeed challenging, partly because of increased random variations between "identical" model tests when waves are near-breaking and breaking. The challenge is further increased if the aim is defining a criterion from the undisturbed incoming wave, at least for floating vessels because of wave diffraction and vessel motions, and a disturbed parameter "coloured" by the influence from the structure may sometimes be a better choice [21]. 
The simplest case is wave-in-deck on bottom-fixed jackets, where the incident undisturbed crest height $A c$ is one obvious and easily defined parameter. This is also a reasonable choice for large-volume bottom-fixed platforms such as GBS, although wave disturbance from diffraction will then be present. This parameter is applied for a GBS in [8], from which the example in Figure 3 is taken where the measured peak global horizontal deck load in each event is plotted against the corresponding undisturbed incident crest height. A certain correlation is seen, although there is also a significant random scatter.
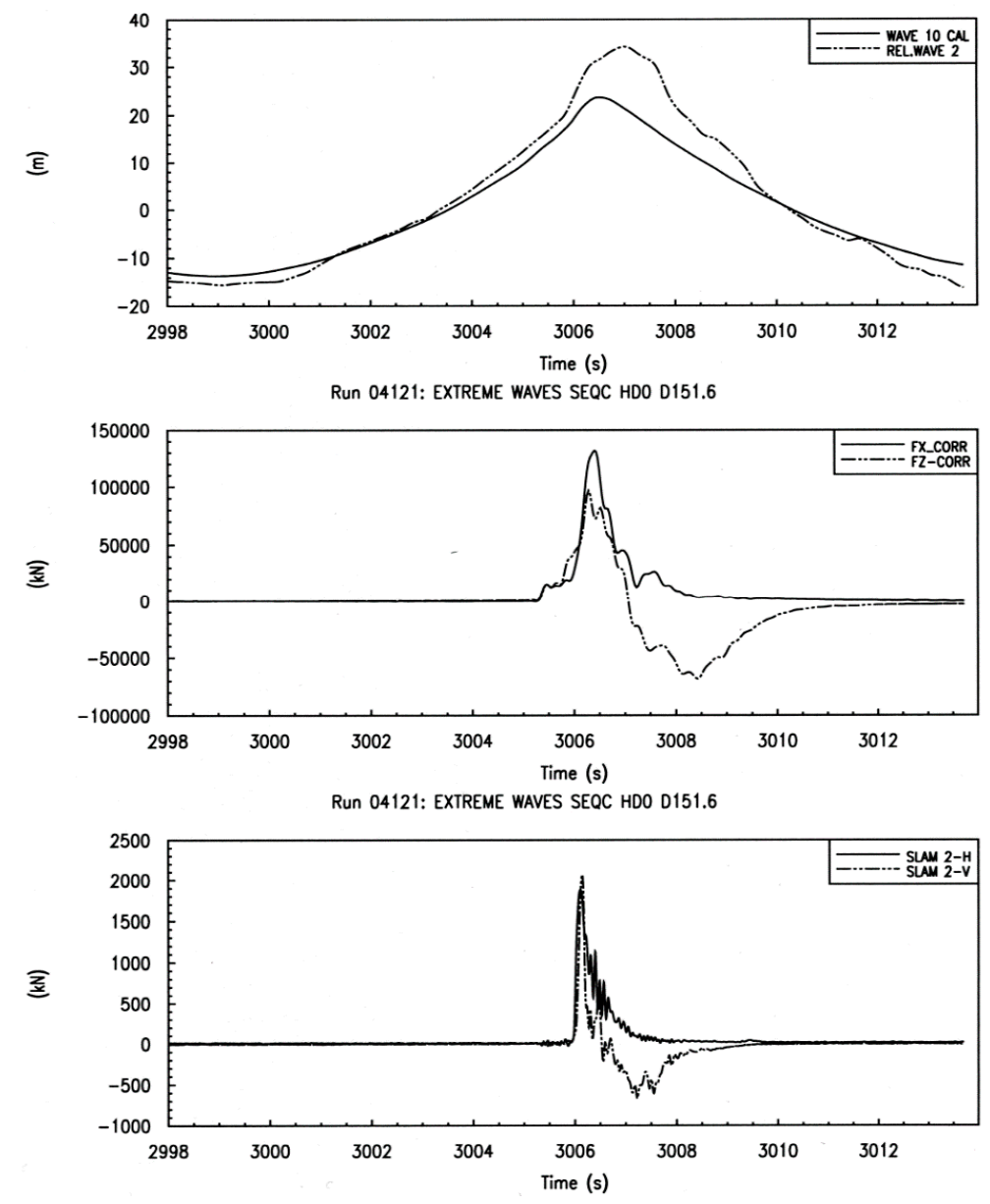

Figure 2. Wave impact event from [8]: (top) incident (undisturbed) and disturbed wave elevation at deck front. (middle): Global horizontal and vertical deck force; and (bottom) local horizontal and vertical slamming force.

Additional suggested undisturbed parameters typically characterise the maximum fluid velocity and/or front steepness of individual waves. Previously, we investigated two different but related such wave event "footprints", one based on a Hilbert analysis treating the local slope $k A$ [20] and one simpler alternative defined as the vertical rise velocity $\partial \eta / \partial t[21,23,24]$.

The latter, easily derived from the wave elevation at a point in space, is addressed in more detail in Section 2 below, together with derived parameters representing simplified engineering deck load models that could alternatively be applied for the screening purposes. The simple hypothesis is that the critical events can be identified from characteristics of the undisturbed wave combined with the overall geometry of the platform and deck. The approach is assuming a rather simplified picture of the real physics: 2D loading with pure potential flow and no local details on the nonlinear diffraction, and no special complexities such as air bubbles (cavities), as observed in [10]. Thus, despite the local details in the wave-structure interaction being neglected, does this approach include the most relevant governing physics for the screening purpose? 
To check and validate this idea, the proposed parameter and formulations are checked in this paper against wave-in-deck impact load data set from the mentioned GBS tests in [8]. A brief review of the tests and set-up is first given in Section 3. Section 4 then presents experimental results on the rise velocity and on peak impact loads, and on their empirical correlation against each other. (In this analysis, the relative wave elevation is for obvious reasons an additional relevant parameter to be included.) The results are further compared to the simplified load formulas, and possible findings for the use in future screening-and thereby reduced need for test data-are addressed. Challenges of the approach are also discussed.

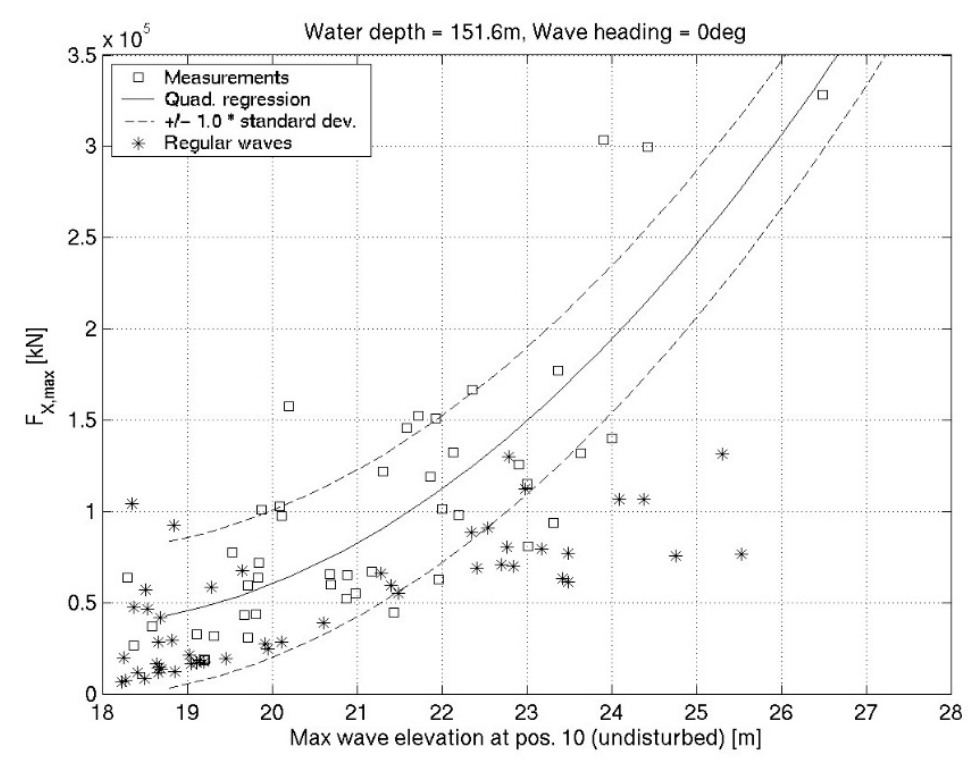

Figure 3. Correlation plot of measured horizontal deck force vs. incident crest. Example from [8].

\section{Methods and Formulations}

\subsection{Wave Steepness Parameter}

Figure 4 illustrates some key characteristics in a wave crest, relevant for wave impact. Our aim is to define a parameter that includes both the wave energy (through the free-surface horizontal orbital velocity $\mathrm{u}$ ) and the geometrical front shape (through the local steepness kA or impact angle $\alpha$ ). One such initiative is presented in [20]: From Wagner's theory $[25,26]$, we know that the local slamming pressure depends on both these two parameters, through the relation

$$
P=\frac{1}{2} \rho C_{s 0} u^{2} \operatorname{cotg}^{2}(\alpha)
$$

where $C_{s 0}$ is the slamming factor and $\rho$ is the water density.

From this, we used the last two factors to define a combined time-varying wave process:

$$
\Psi(t)=u_{0}(t)^{2} \cdot\left[k_{0}(t) A_{0}(t)\right]^{2} \equiv C_{p}^{2}(t) \cdot\left[k_{0}(t) A_{0}(t)\right]^{4}
$$

where $C_{\mathrm{p}}$ is the celerity (phase velocity) and $u_{0}, k_{0}$, and $A_{0}$ are the linear horizontal particle velocity, wave number, and amplitude, respectively.

In [20], it is demonstrated that this "wave impact parameter" is reasonably well connected with various real impact types from model test data. For practical use, however, there are other and simpler alternatives that express more or less the same properties. Here we shall consider the vertical rise velocity $\partial \eta / \partial t[21,23,24]$, as measured by, e.g., a fixed wave probe.

For a deep-water linear regular wave, it can be easily shown that $\partial \eta / \partial t$ is similar to the horizontal and vertical velocity components $u_{x}$ and $u_{\mathrm{z}}$ at the free-surface, except for a phase shift of $\mathrm{u}_{\mathrm{x}}$. The full 
lines in Figure $5 \mathrm{a}$ (middle and lower plots) demonstrate this for the $u_{x}$ case. For a second-order regular wave (dashed lines in the same plots), the rise velocity time profile shape is no longer identical to $u_{x}$ but the peak values are still quite similar.

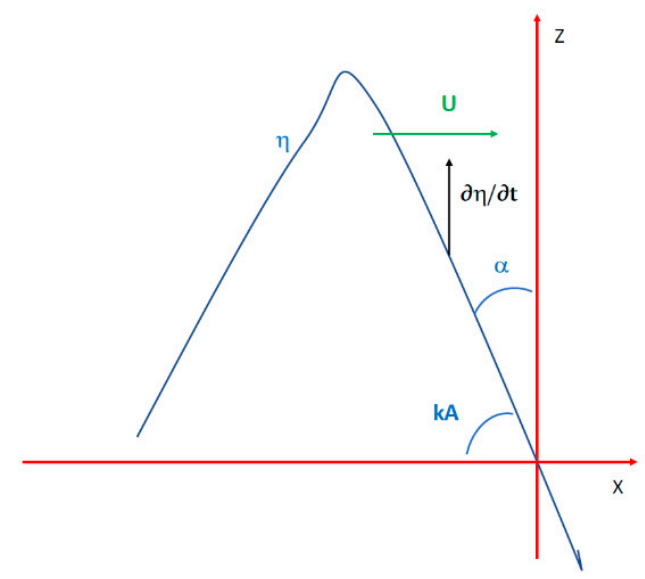

Figure 4. A selection of local wave parameters (based on [21]).

In deep-water linear and second-order irregular waves (using the formulation in [27]), we see a corresponding similarity between the peak values of $u_{x}$ and $\partial \eta / \partial t$ in Figure $5 b$ (middle and lower plots), although $\partial \eta / \partial t$ peak values are slightly on the lower side, while time profiles are clearly different. These observations indicate that the rise velocity may be a useful parameter reflecting the horizontal kinematics in measured waves, in addition to being a useful parameter for the local slope $\partial \eta / \partial x$ through the following estimate, assuming a "frozen" wave profile over a short time interval:

$$
\partial \eta(t) / \partial t=\left(\partial \eta(t) / \partial x \cdot C_{p}(t)\right.
$$

(note that the orbital velocity and the local slope are usually closely related). Therefore, in the experimental data analysis described in the following sections, we make use of this wave parameter as well as of a derived, simplified wave-in-deck load model that is described below. As shown below, the proposed model is basically related to the previously investigated impact parameter $\Psi$ in Equation (2) [20].

\subsection{Simplified Horizontal Wave-in-Deck Load Model}

In the following, we address the relevance of the rise velocity in wave impact problems as seen from a theoretical point of view. We propose a simplified two-dimensional (2D) formulation of the peak value of the wave-induced, local horizontal slamming pressure from a long-crested head sea wave impact on a finite vertical wall, based on Equation (1) and on:

(i) an assumed relationship and similarity between the vertical rise velocity $\partial \eta / \partial t$ and the free-surface orbital velocity $u$; and

(ii) the fact that the orbital velocity $u$ can, at least in a linear regular wave, be written as the product of the phase velocity and the local steepness (slope) $\partial \eta / \partial x=k A$ :

$$
u=C_{p} \cdot(k A)
$$



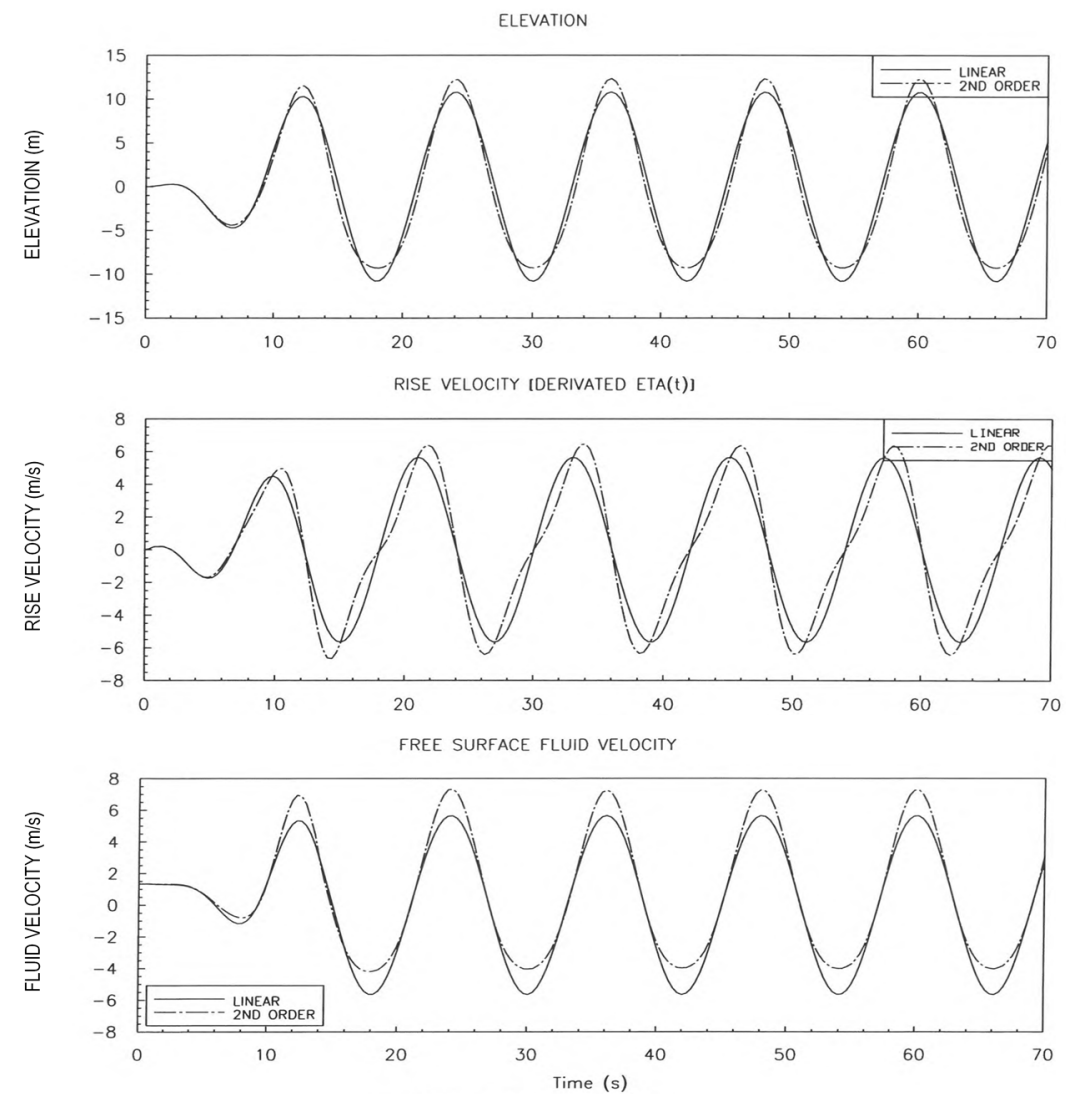

(a)
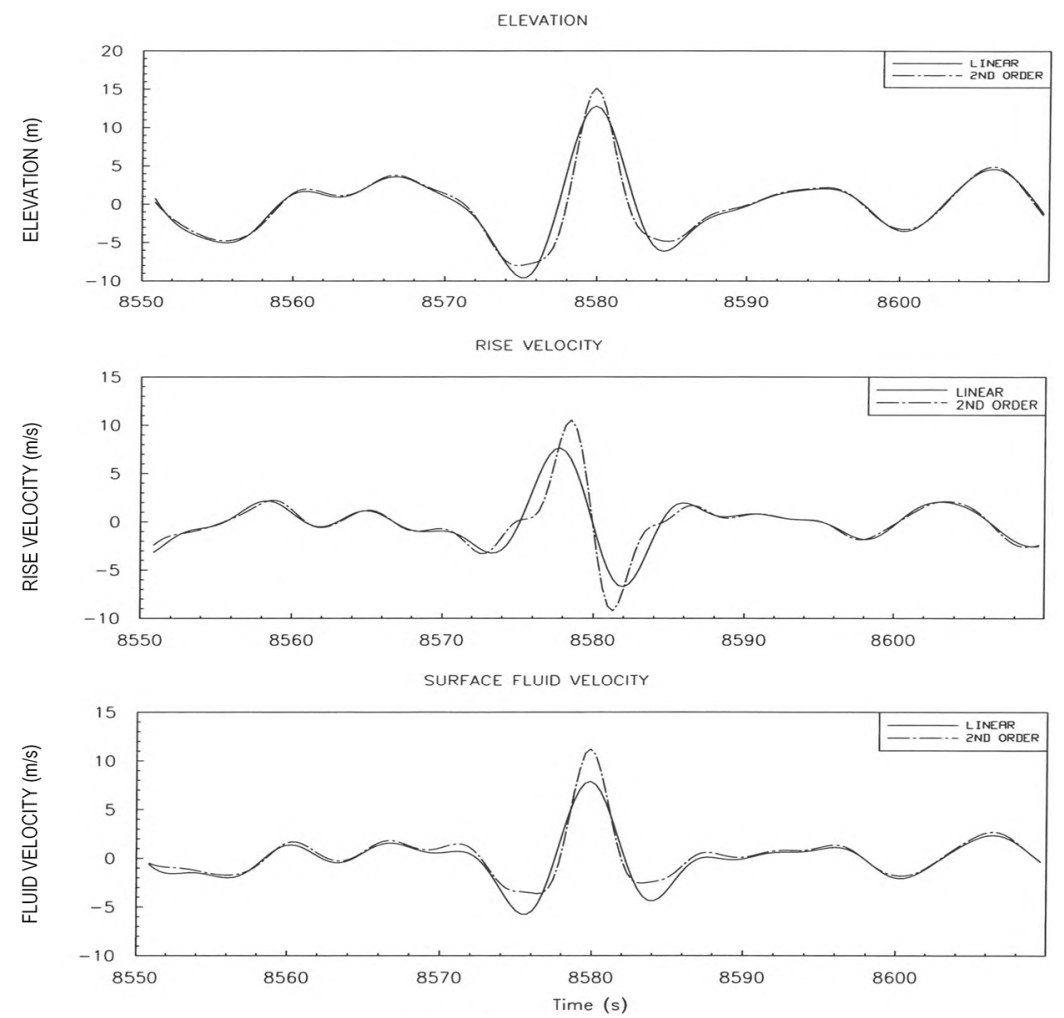

(b)

Figure 5. Time series examples of wave elevation, rise velocity, and free-surface horizontal fluid velocity. Numerical linear and second-order wave models: (a) steep regular wave; and (b) steep irregular wave. 
Thereby, when we include also the hydrostatic pressure $P_{0}(h)=\rho g h$, where $g$ is the acceleration of gravity and $h$ is the immersion depth at the time and point of observation, our suggested total local slamming pressure formula finally reads:

$$
P(h)=\rho g h+\frac{1}{2} \rho C_{s 0} \cdot[\partial \eta / \partial t]^{4} / C_{p}^{2}
$$

For the slamming coefficient $C_{s 0}$, Wagner theory $[25,26]$ gives:

$$
C_{s 0}=(\pi / 2)^{2}
$$

Note that here we assume no vertical variation in the slamming pressure contribution (the second term) from a given wave. This is certainly a simplification which we need to keep in mind. The formulation further assumes a 2D scenario, expressing the local impact based on the local characteristics of the long-crested incoming wave. This is also a simplification of the real world. There will certainly be additional 3D effects determined by the geometry of the structure. However, our hypothesis is that the formulation describes the main underlying physics, which can be useful for a quick analysis such as screening. The hypothesis is checked by experimental validation in Sections 3 and 4 .

The formulation in Equation (5) should at least be a reasonable choice for linear regular waves and our suggestion is that it also works for any types of regular and irregular wave records, including model test waves where nonlinear effects can be important. This extension from linear regular waves to nonlinear irregular waves is of course not immediately obvious, but the logic behind the idea is that the slamming is defined by the square of the relative fluid velocity in combination with the relative angle. Herein, we do not assume anything about linearity since both critical parameters are "baked into" the rise velocity formulation for both linear and nonlinear waves, thus we believe that it could work at least to some extent when properly calibrated against experimental data.

For the celerity $C_{p}$ in an irregular sea state, one should ideally use the local time-varying velocity at the instant of the impact. However, this is often complex to estimate directly from measured records, and for simplicity we use here the celerity of the sea state spectral peak wave period, $T p$.

As compared to the impact parameter of Equation (2), we see that the present one basically expresses similar physics, but it is much simpler to use for measured waves, and it also represents direct estimates of physical pressures.

In measured waves, local wave pressures expressed through Equations (1) and (5) will exhibit large horizontal and vertical spatial variations, partly due to local variations in the relative impact angle $\alpha$ (i.e., the local $k A$ ). For spatial averages over finite areas, which we in practice interpret to be typically $\sim 10 \mathrm{~m}^{2}$ and somewhat larger (full scale), DNV GL [7] recommends that, rather than Equation (1) the following formula should be used:

$$
P=\frac{1}{2} \rho C_{s 0} 0^{\prime} \operatorname{cotg}^{1.1}(\alpha)
$$

where $C_{s 0}{ }^{\prime}$ was slightly adjusted to 2.5 rather than $(\pi / 2)^{2}$. (Note that, for a quite steep nonlinear wave with local slope $45 \mathrm{deg}$, Equations (1) and (7) give the same pressure results). Instead of Equation (5), we obtain then for the total spatially averaged pressure estimate:

$$
P(h)=\rho g h+\frac{1}{2} \rho C_{s 0^{\prime}} \cdot[\partial \eta / \partial t]^{3.1} / C_{p}^{1.1}
$$

By integrating the pressure over the whole wetted area of a large platform deck wall, we also obtain an estimate of the global, horizontal deck impact force. However, over such a large (global) area, the above formulation is a too serious simplification. Local 3D variations in a steep wave impacting on a vertical structure lead to lower average pressure with increasing area. This is particularly the case for breaking and near-breaking waves. The presence of a large-volume substructure will further enhance 
3D spatial variation effects. Furthermore, from the definition of Equation (7) (from [7]), at least for angles $\alpha$ larger than $45 \mathrm{deg}$, it is reasonable to assume some vertical reduction in the upper parts of the slamming pressure contribution. Thereby, the use of the local expressions in both Equations (5) and (8) will likely be too conservative over a very large area. In the case with a large platform deck of size 50-100 m, we choose to compensate for this by proposing Equation (8) but now with a simplified, empirical overall reduction factor of 2.5 for the second (slamming) term (which is the most important one). Thereby, we obtain the following for the spatially integrated horizontal force peak:

$$
F x=1 / 2 \rho g Z_{D}^{2} L+1 / 5 \rho Z_{D} B C_{s 0^{\prime}} \cdot[\partial \eta / \partial t]^{3.1} / C_{p}^{1.1}
$$

where $B$ is the width of the wetted deck wall and $Z_{D}$ is the maximum wetted height at the lateral deck centre, measured from the lower edge of the wall. However, we must keep in mind that this area approximation is certainly a simplified choice, and there are still uncertainties related with this formulation being applied over a large platform deck full width. Again, the idea is that such a formulation for the global horizontal force can be useful for a fast and analytical check, e.g., for screening of critical events in a sea state, and this is checked against experiments in the next sections. For detailed wave impact analysis, however, more accurate and detailed approaches should normally be used.

The impact load formulation in Equation (1), and thereby also our derived pressure and force formulations in Equations (5) and (9), has clear apparent similarities to the well-known API simple silhouette formula [5], although the latter is known as a drag formulation. In practical use, we see that our formulation technically is related to a generalisation of the API formula, with the force coefficient in the latter replaced by $C_{s 0} \operatorname{cotg}^{2}(\alpha)$ (for the local pressure) and $0.4 C_{s 0}{ }^{\prime} \operatorname{cotg}{ }^{1.1}(\alpha)$ (for the integrated force over a very large deck wall). In addition, we also include a hydrostatic term.

Equations (5) and (9) both express a very strong sensitivity to the peak rise velocity. This supports, as shown by the experimental results, the idea that the slamming term is clearly the dominating one in steep waves. It also means that the slamming forces will, as confirmed from many previous experiences, exhibit a large random variability since the exact impact angle $\alpha$ and velocity $\partial \eta / \partial t$ can vary a lot locally for a steep wave impact on a wall. It can also vary between repeated experiments.

Since the present formulation is $2 \mathrm{D}$, it assumes head-on waves. For oblique wave incidence (which will usually reduce the slamming loads), it must be generalised to include the effect of the relative wave direction, which we denote with $\theta$. One possible rational approach for such cases would be to replace the 2D impact angle $\alpha$ with the effective, increased 3D relative angle of the wave front surface, resulting from the combination of $\alpha$ and $\theta$. This could be a matter for further work.

\section{Experimental Test Case: Wave-in-Deck Loads on GBS}

To check the proposed impact force model, we make use of existing wave-in-deck load data from Statoil's GBS model tests carried out in MARINTEK's Ocean Basin and previously described in 2004 [8]. The purpose in the present study is to investigate the possible correlation between observed rise velocities and resulting horizontal slamming loads, and how well this correlation is described by the formulations in Section 2. The original tests themselves were made to verify the platform integrity with respect to wave-in-deck events in $10^{-4}$ annual probability storms in the northern North Sea (sea states relevant for this area are indicated in Figure 1), in a scenario with $1.5 \mathrm{~m}$ future bottom subsidence. Hence, tests were made in two water depths: 150.1 and $151.6 \mathrm{~m}$. The corresponding still-water air-gaps to the cellar deck were then 23.2 and $21.7 \mathrm{~m}$, respectively, while the underside of deck frame was $2 \mathrm{~m}$ lower, as indicated through the sketch in Figure 6. Eventually, as it can be read from [8], based on the tests, the structural analysis concluded that the platform can sustain a subsidence of $1.50 \mathrm{~m}$ without losing its load bearing capacity.

We focus here mainly on the horizontal hydrodynamic wave-in-deck impact forces only, and not on the platform as such. It is of importance, however, to know that the large-volume substructure with columns and caisson will amplify the waves due to diffraction, which in steep waves can include 
significant nonlinear contributions. The latter was investigated for these GBS tests in $[8,28]$, and is also briefly addressed in Section 3.2.

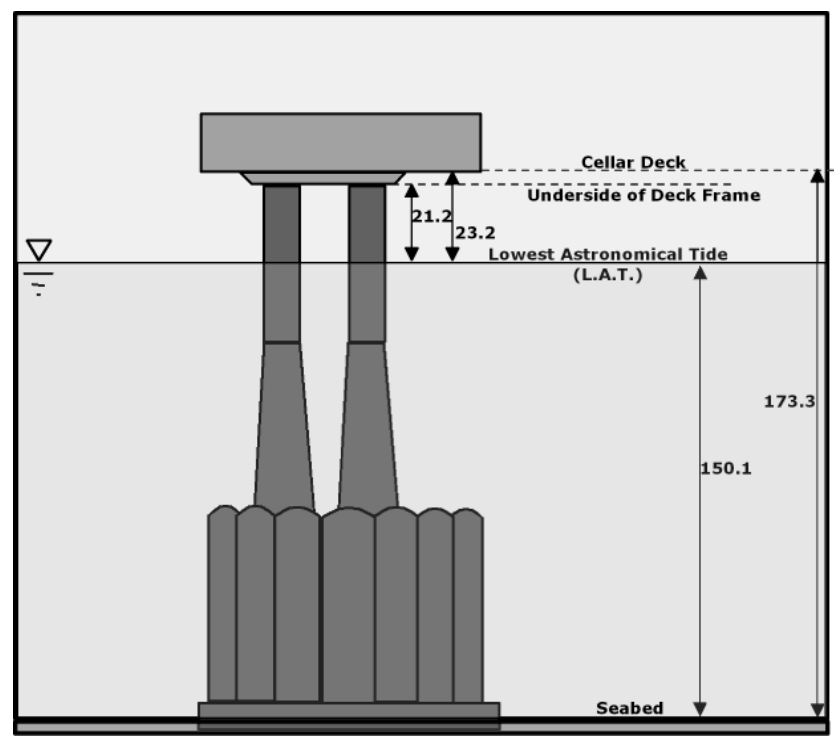

Figure 6. Schematic illustration of the GBS with key data, original condition (full scale) [8].

\subsection{Brief Review of Experiment}

The model scale was 1:54. The whole model structure was rigidly bottom-mounted to a stiff tailor-made steel truss foundation. A set of force sensors mounted between the deck and the substructure columns measured six degrees of freedom (6 DOF) global deck forces at a sampling rate of $250 \mathrm{kHz}$ (model scale). Horizontal and vertical local slamming forces were measured by $7.5 \mathrm{~m}^{2}$ stiff force panels at a sampling rate of $2 \mathrm{kHz}$. They were located at the lower part of the upwave cellar deck wall and under the cellar deck, respectively.

Here, we only address measured horizontal global and local loads; for the latter, we use data from one force panel at the horizontal centre of the wall just above the cellar deck level. We include results from tests in both 150.1 and $151.6 \mathrm{~m}$ water depths, in one heading only ( $0 \mathrm{deg}$ ).

The main tests, which are considered here, included one long-crested $10^{-4}$ irregular storm sea state, with $H \mathrm{~s}=18.2 \mathrm{~m}$ and $\mathrm{Tp}=17.0 \mathrm{~s}$. Wave pre-calibration was done with $20 \times 3$-h (full scale) realisations to provide robust statistics. In the tests with the model installed, however, one used compressed wave records including only wave groups with high maximum crests $\mathrm{A}>18 \mathrm{~m}$ (undisturbed). Such events occurred roughly around 2-3 times within a 3-h interval. More details on this approach are given in [8]. In addition, a set of regular waves were also run from which a few are selected for this presentation.

Waves were measured by conductance wave staffs at a sampling rate of $250 \mathrm{kHz}$. The derivation to obtain rise velocities from elevation was numerically processed by a frequency-domain low-pass filter at $15 \mathrm{~Hz}$ (model scale), which we chose as a reasonable compromise between keeping the signal noise level low and with most of the real velocity signal still remaining. The resulting peak velocity values are to some extent sensitive to the actual filter cut-off frequency. We found that a $20 \mathrm{~Hz}$ cut-off will typically increase the relevant peaks by an order of $5 \%$ (depending on the events), while $10 \mathrm{kHz}$ reduces them by typically $20 \%$. Thereby, the resulting velocities are not considered as exact, unique values, but rather as approximate estimates, possibly slightly on the low side. The actual filter corresponds to a local time-averaging within a time interval of roughly $0.4 \mathrm{~s}$ (full scale). For a consistent interpretation of the correlation against loads, it is important that all records are processed with exactly the same filter.

Figure 7 shows a wave-in-deck event from the tests. The shown case is a near-breaking (at this point in space) and quite steep wave. It is not among the most extreme of observed wave impact events; rather a "typical" one selected from the large set (which is still a serious event since it in fact hits the 
deck). Initially, it reached only slightly higher than the cellar deck, but when it hits the lower part of the deck a tongue of green water is seen upwelling on the wall, leading to a significant horizontal deck load. In the most severe events wave breaking also occurred.

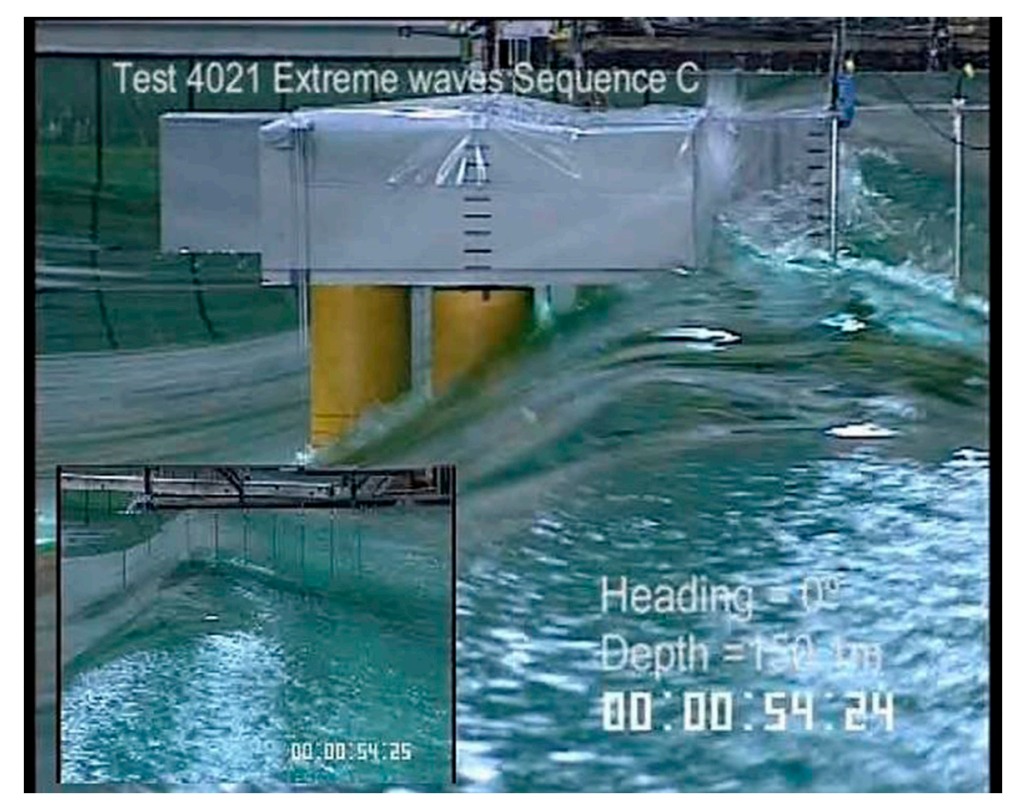

Figure 7. Frozen video frame with random wave impact event on GBS deck. Calibrated wave inserted left.

\subsection{Practical Use of Slamming Load Formulation}

We need to establish the proper practical parameters for the application of the slamming formulation expressed in Section 2.2, for this platform case. Thereby, for each impact event, values are determined for the maximum local immersion depth $h$ in the local hydrostatic pressure of Equation (5), and for the maximum wetted height $Z_{D}$ in the integrated force of Equation (9).

For the immersion depth $h$, we choose to define it from the centre of the $7.5-\mathrm{m}^{2}$ slamming force panel and up to the maximum amplified (diffracted) crest height $A_{D}$ during the event. We stipulate this centre, which we define as a zero level for our calculation, to be $2 \mathrm{~m}$ above the cellar deck level, i.e., at 25.2- and 23.7-m levels for the two water depths of 150.1 and $151.6 \mathrm{~m}$, respectively.

For the wetted wall height $Z_{D}$, we define it from the bottom of the girders that reach $2 \mathrm{~m}$ below the cellar deck (see Figures 7 and 8), i.e., at 21.2 and $19.7 \mathrm{~m}$, respectively, for the two water depths, and up to the maximum amplified crest height $A_{D}$. The deck width $B$ is $83.6 \mathrm{~m}$.

The amplified crest height $A_{D}$, as measured from the still sea level, is a result of the incident crest height $A_{W}$ in combination with global diffraction from the substructure (columns and caisson) and a local upwell amplification effect due to the deck impact, as observed in Figure 6. Measured $A_{D}$ are in fact available from relative wave probes in front of the wall, but we rather choose to use a simplified calculation of $A_{D}$ here, which can be used directly on the incident wave record without any pre-knowledge from the actual platform model tests, as follows: Supported by the empirical formula for amplification near columns presented in [29], we suggest $A_{D}=1.33 \cdot A_{W}$ in the present application. This includes both linear and nonlinear diffraction contributions, and is an average factor applied over the full deck width; in reality it is highest in the centre and decreases to the sides.

This factor choice agrees roughly with findings in steep regular waves previously published from this case in [8,28], indicating amplification factors of around 1.2-1.4 due to columns and caisson. We also found it to be similar to actual observed factors in the present irregular waves, except for the highest and steepest waves hitting the deck where it is slightly non-conservative at the lateral centre due to the local upwell on the wall. We should keep this in mind, but there is an uncertainty about 
the relevant water height at the very peak of the measured water level on the deck wall in such cases, with the probe close to the wall, and we should also note that our present theoretical model is a clearly simplified one with several other assumptions as well. In any case, we believe that our choice overall reflects the governing physics of the phenomenon.

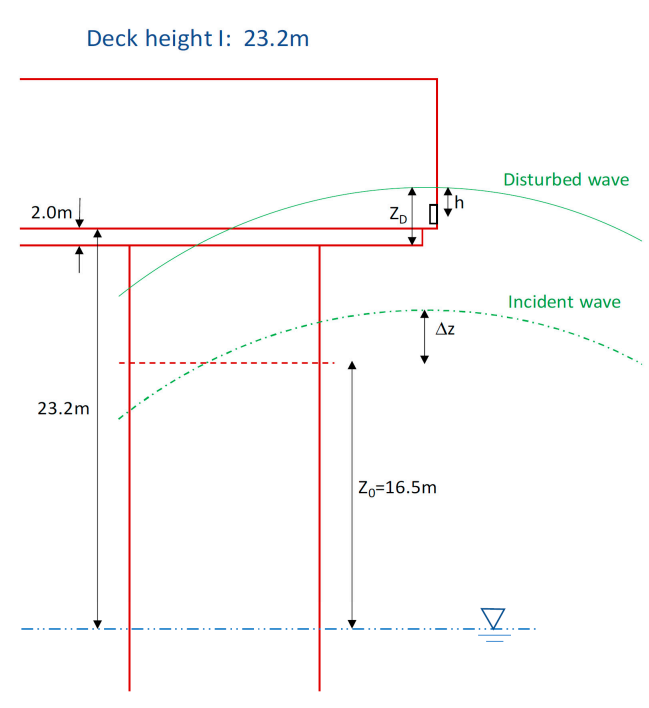

(a)
Deck height II: $21.7 \mathrm{~m}$

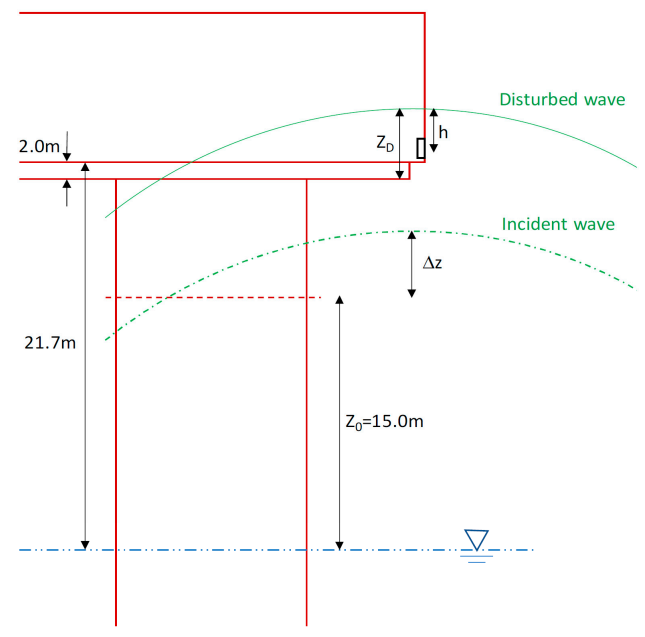

(b)

Figure 8. Schematic illustration of the height levels on platform, with upwave part of platform shown for two deck heights: (a) cellar deck height $23.2 \mathrm{~m}$ (i.e., water depth $150.1 \mathrm{~m}$ ), and (b): cellar deck $21.7 \mathrm{~m}$ (i.e., water depth $151.6 \mathrm{~m}$ ). Symbols are defined in the text. Approximate geometrical scale only.

Thereby, 18- and 19.5-m incident crest heights will reach 24 and $25.5 \mathrm{~m}$, respectively, which are just above the force panel centre in the two different water depth cases of 151. and $150.1 \mathrm{~m}$. Similarly, 15- and 16.5-m incident crest heights will reach to 20 and $21.5 \mathrm{~m}$, respectively, which are just above the girder bottoms in the two cases.

In the final comparison of results (Section 4.3), we shall combine the results for the two water depth cases, defining a "zero-level" incident crest height $z_{0}$ such that $A_{W}=z_{0}+\Delta z$. We choose $z_{0}$ to be 15 and $16.5 \mathrm{~m}$ for the 151.6 and $150.1 \mathrm{~m}$ depth cases, respectively, i.e., at the lowest crest height levels that will hit the deck according to $A_{D}=1.33 \cdot A_{W}$. Figure 8 gives a schematic illustration of the height levels $h, Z_{D}, z_{0}$ and $\Delta z$, for each of the two water depths. The combination of data from two test sets is reasonable since the water depth difference is quite small compared to the crest heights.

\section{Results with Discussion}

The results and discussions in the following include, firstly, selected illustrating time series of: the incident wave elevation $\eta(t)$, the derived rise velocity $\partial \eta(t) / \partial t$, global horizontal deck forces $F_{g l o b a l, X}(t)$ and local horizontal slamming forces $F_{\text {slam }, X}(t)$. Processed peak values follow then, presented through correlation plots which also include comparisons to the theoretical, simplified models in Section 2.

\subsection{Time Series, Regular Waves}

Figures 9 and 10 show time series for regular waves with $H=10 \mathrm{~m}, \mathrm{~T}=15.5 \mathrm{~s}$ and $\mathrm{H}=40 \mathrm{~m}$, $\mathrm{T}=17 \mathrm{~s}$, respectively. In the former low-steepness case, both the elevation and rise velocity look harmonic, i.e., little nonlinearities. No deck impact occurred. In the latter high-steepness case, both wave and velocity signals show more nonlinearities with clear asymmetry details, and the crests were also high enough to hit the deck, as we see from the two lower record plots. Local average pressures can be derived from the lowest plot through dividing by the panel area of $7.5 \mathrm{~m}^{2}$; thereby, we see that wall pressures are in a range around $\sim 100 \mathrm{kPa}$ in these very high regular waves. The time variation in 
peak forces is related with an only slight variation in wave crests; this demonstrates how sensitive the load is to the inundation. For the global force, this is also evident from our model Equation (9). For the local force, our model in Equation (5) does partly include it through the hydrostatic pressure, but it disregards possible vertical variation in the slamming pressure.
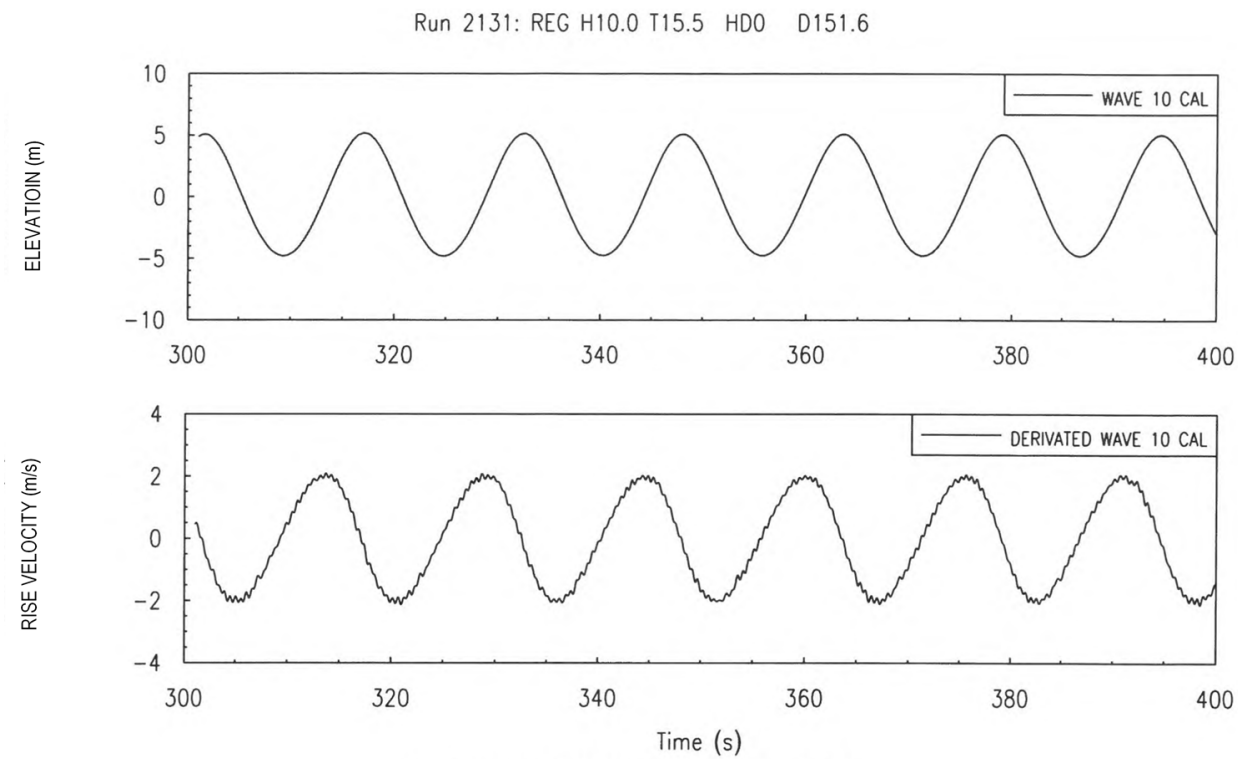

Figure 9. (Top) Measured incident wave elevation for a low regular wave $\mathrm{H}=10 \mathrm{~m}, \mathrm{Tp}=15.5 \mathrm{~s}$.

(Bottom) Corresponding rise velocity derived from the elevation.

Rapid oscillations (ripples) with periods of roughly $0.7 \mathrm{~s}$ (full scale) occur in the rise velocity signal in Figure 10, and can also just be observed in the elevation but to a much less extent. These look very similar to those described by Longuet-Higgins [30], in which several other references are also given on this subject. He described and discussed ripples from combined capillary and viscous wave effects that can occur at the surface in steep regular waves, connected with the formation of spilling breakers. The study in [30] indicates that such effects can in fact occur in relatively long gravity waves, of several meters lengths. His explanation agrees with our observation that they occur only in the wave fronts. If they are a real physical wave effect, as they appear to be, it should be reasonable to relate them physically to the measured impact loads; in such a case, they do represent a scaling challenge. However, we still see uncertainties with this explanation, and it should be further studied. Based on the description of the phenomena in [30], we also interpret that they may be less relevant in steep breaking and near-breaking rogue waves in irregular seas where other phenomena may dominate. Such events are presented in Section 4.2, where we show that those results do not indicate clear ripple effects in the steepest crests. However, some studies $[14,15]$ do indicate that viscous and surface tension effects can in general affect such rogue waves, leading to reduced orbital velocities near the breaking crest, and thereby also resulting forces, in real conditions.

We found, as a support to the above capillary/viscous wave effect explanation, that the ripples are likely neither an instrumental nor a signal filtering effect: the oscillation period has been found to vary with the wave condition but not with the filter characteristics, and they are just observable also in the elevation signal (less pronounced here since the derivation filter amplifies the signal at higher frequencies). We also considered possible wake disturbances from the upwave wave probe frames as an alternative source, but such effects would be expected to be observed also aft of the crests.

In Figure 10, we observe a slight time lag between the global and local force peaks. A likely explanation is the global horizontal force contribution from $2 \mathrm{~m}$ high girders installed underneath the model deck. These effects are not included in our global force model Equation (9), and should be kept in mind for the later comparisons. 

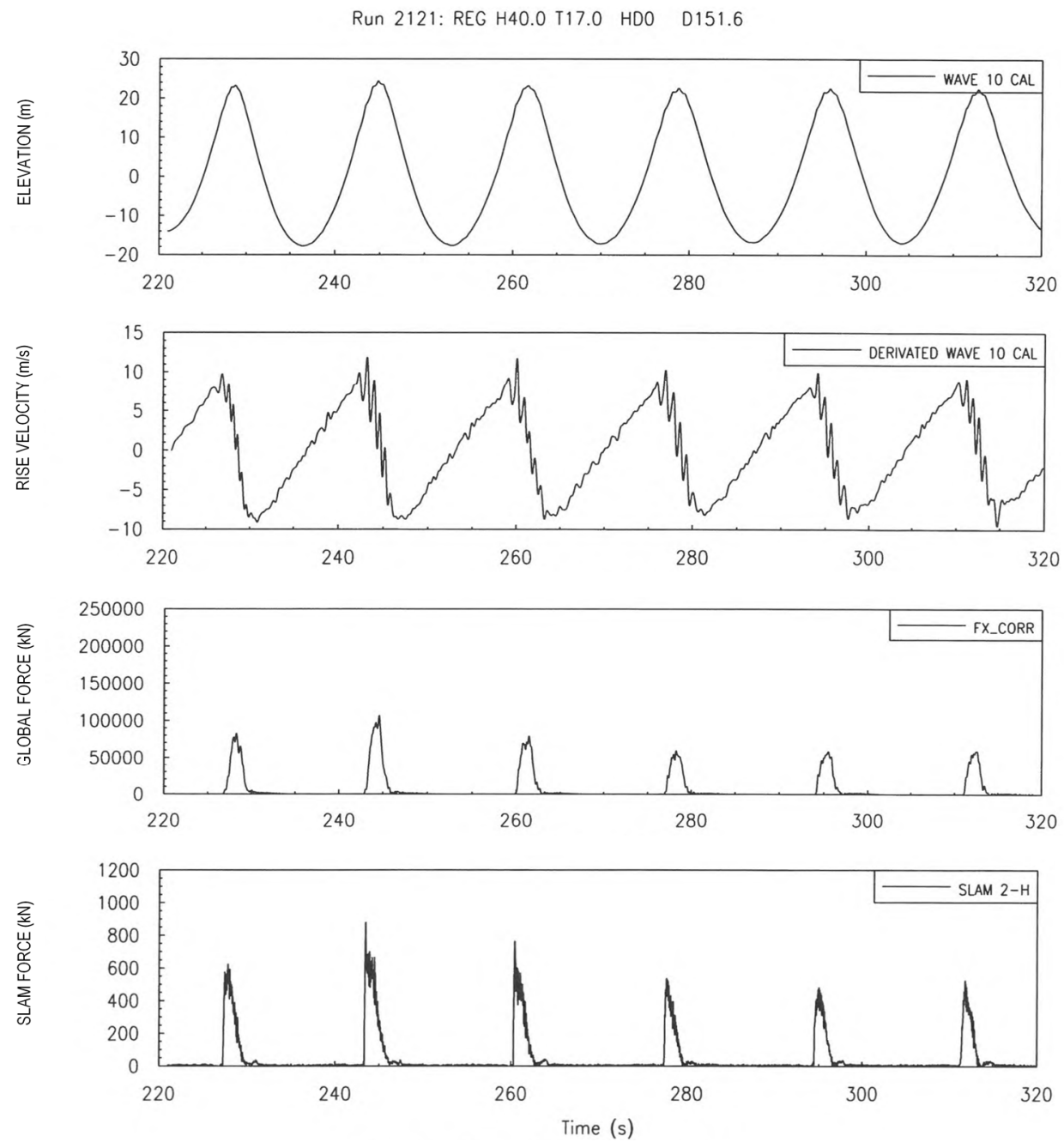

Figure 10. From top to bottom: Measured undisturbed wave elevation, derived rise velocity, global horizontal deck impact force, and local horizontal slamming forces, for a high regular wave $\mathrm{H}=40 \mathrm{~m}$, $\mathrm{T}=17 \mathrm{~s}$.

\subsection{Time Series, Irregular Waves}

Plots similar to those shown for the regular wave in Figure 10 are shown in Figures 11 and 12, for four different wave impact events, denoted with a-b-c-d, in the irregular wave $\mathrm{Hs}=18.2 \mathrm{~m}$ and $\mathrm{Tp}=17.0 \mathrm{~s}$. Figure 11a shows a high, symmetric wave event with a moderate-to-high steepness. The rise velocity and impact forces at the crest peak are in this case similar to those for the high regular wave in Figure 10. The wave in Figure $11 \mathrm{~b}$ is also symmetric but higher and with a steeper crest. In this case, the rise velocity and deck forces are increased. There is a rapid peak in the rise velocity, not seen in the previous (upper plots) case.

Both wave cases in Figure 12c,d are steep-fronted high waves, which result in very high rise velocities up to $25-30 \mathrm{~m} / \mathrm{s}$ as well as high global and local impact forces. These events are two of the most extreme cases among the total dataset. The examples in Figures 11 and 12 indicate at least qualitatively that high rise velocities seem to be correlated with high deck impact forces. This correlation is investigated further in Section 4.3. Similar rise velocity profiles have also been observed for both measured and computed breaking waves in [8]. 

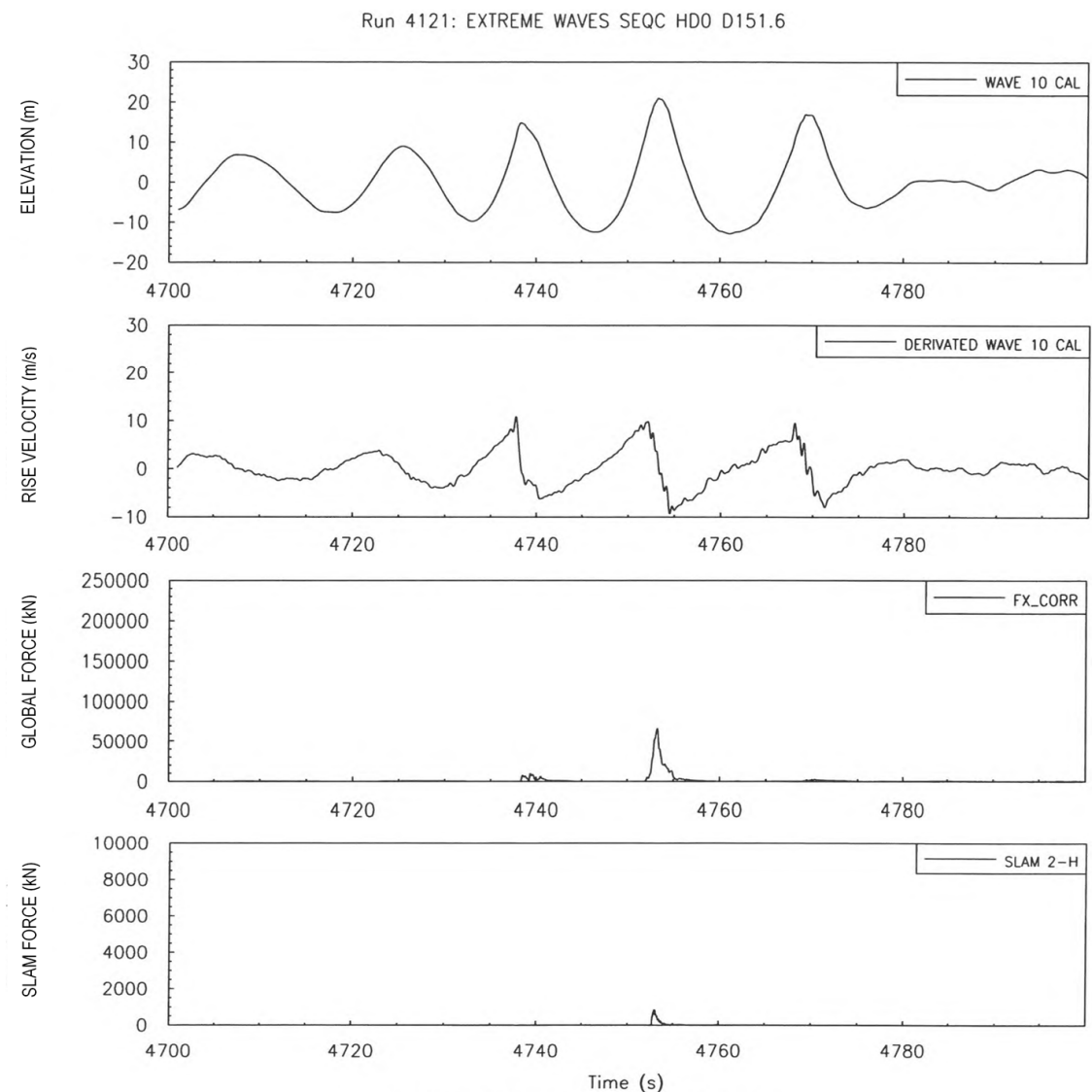

(a)
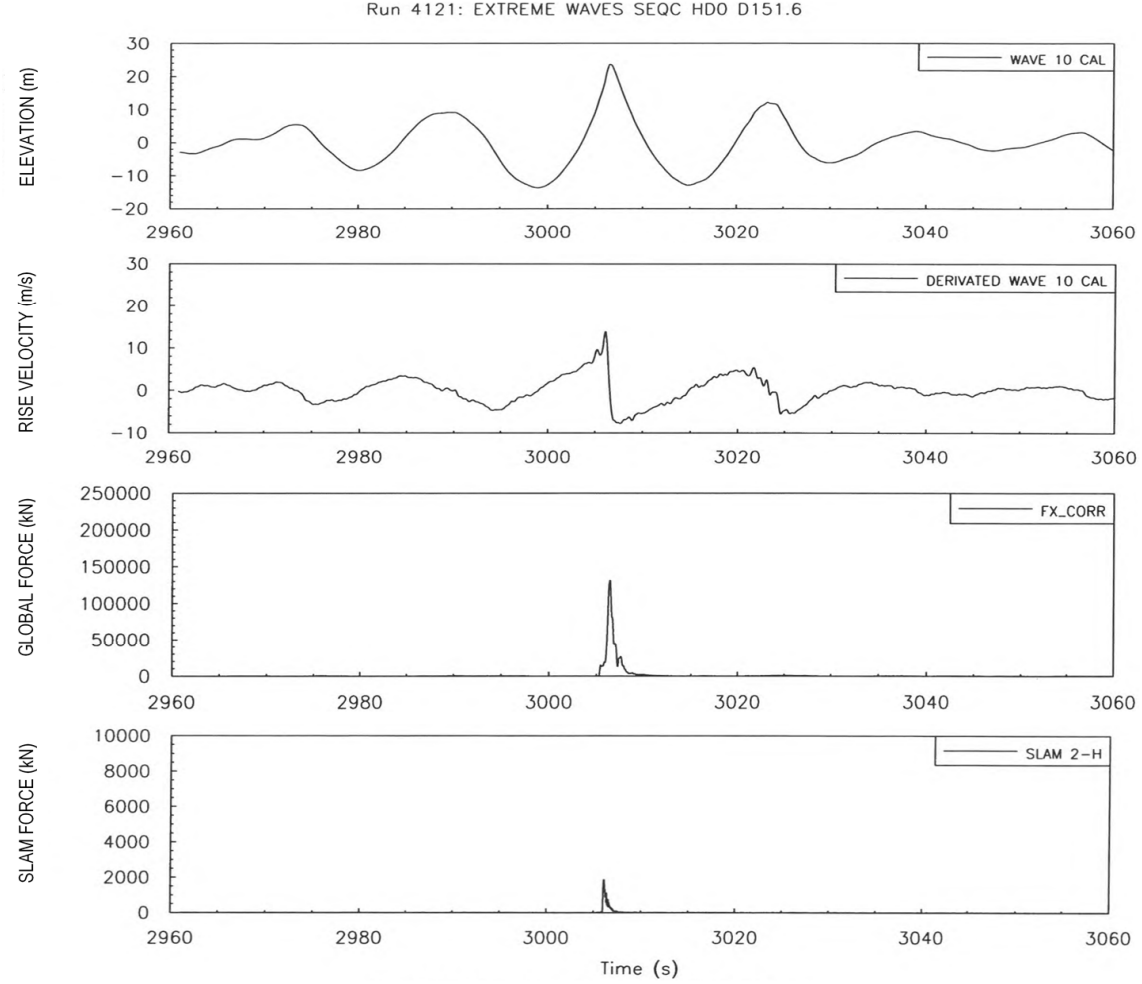

(b)

Figure 11. The same as Figure 10, but for two irregular wave events (a,b). 

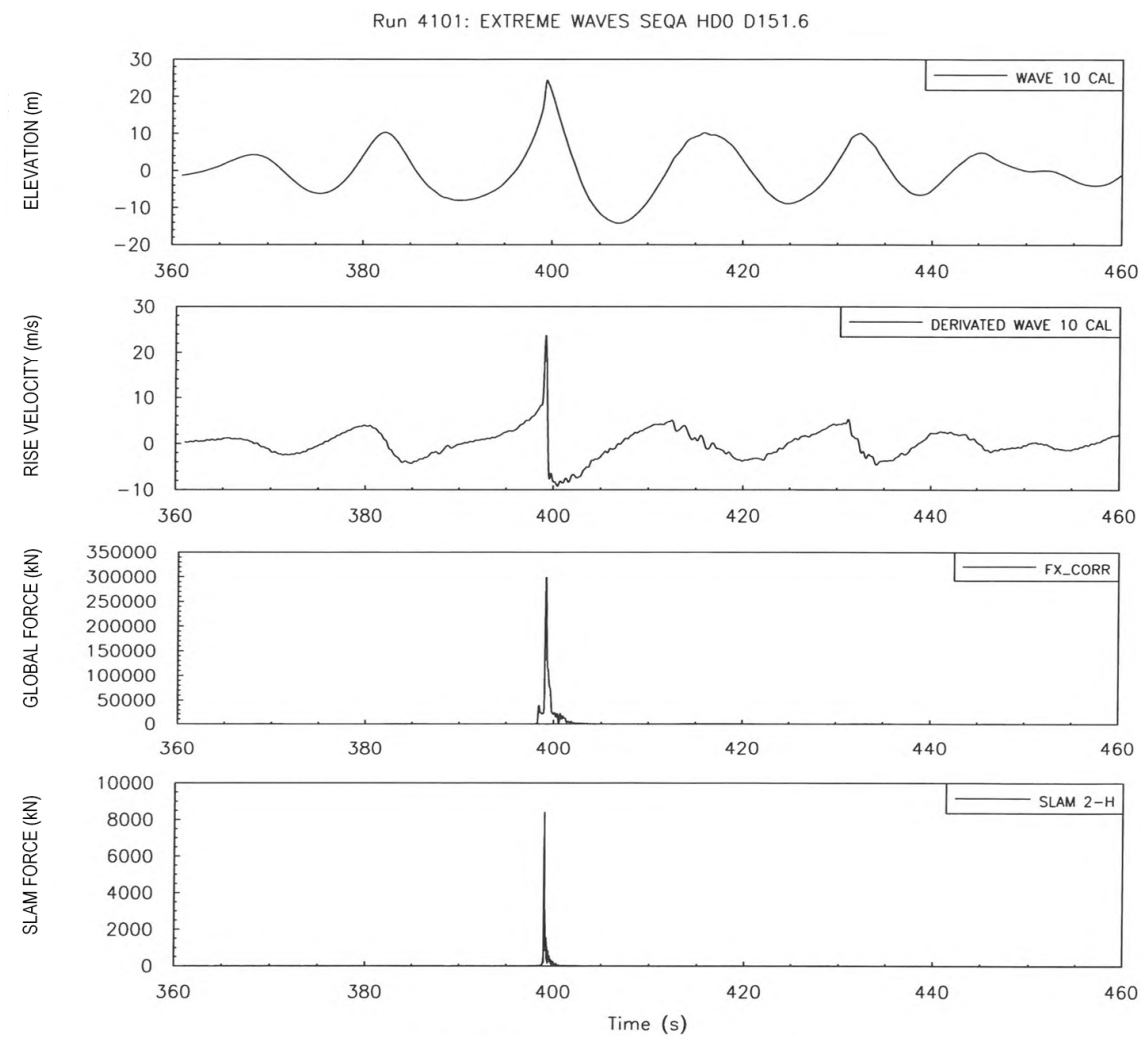

(c)
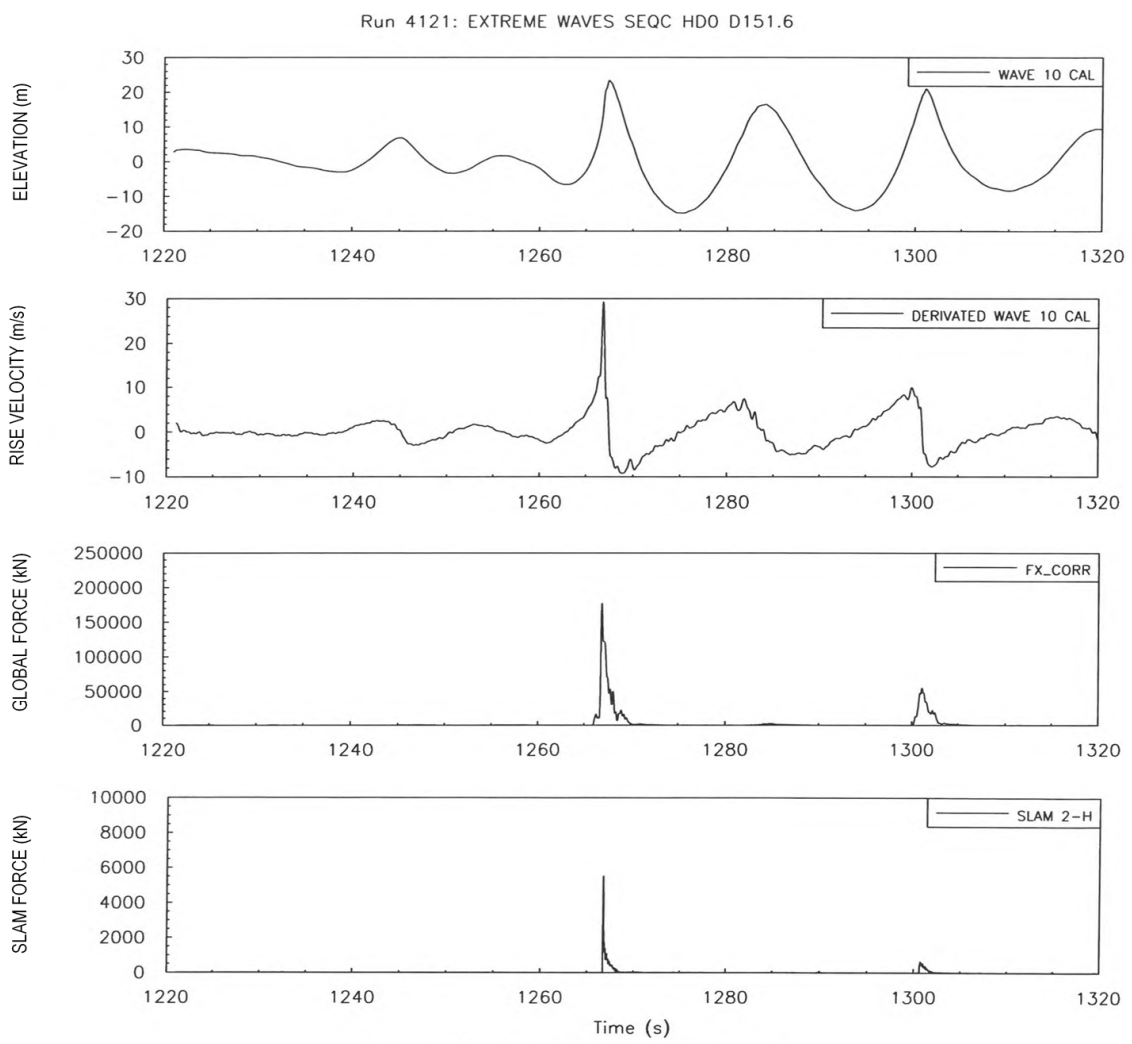

(d)

Figure 12. The same as Figure 10, but for two irregular wave events (c,d). 
Furthermore, the two waves in Figure 12 are probably breaking near the platform, although the maximum impact pressures from a breaking wave, which can be many MPa in such sea states $[3,18,31]$, hits at lower positions than the present deck, e.g., on columns. In the present problem, the deck is hit by the upper crest peak of the wave (see Figure 7) where the pressure is somewhat lower. The present local slamming panel forces indicate around 1 and $0.5 \mathrm{MPa}$, respectively, in these two extreme cases. Pressures are found from dividing the panel force by the panel area $7.5 \mathrm{~m}^{2}$.

For the latter two cases we observe peak rise velocities in the range $25-30 \mathrm{~m} / \mathrm{s}$. This is slightly higher than the corresponding phase velocity $C p(\approx 20 \mathrm{~m} / \mathrm{s})$ as observed from two neighbouring wave staffs. (Note that for the $17 \mathrm{~s}$ regular waves, $C p$ was $\approx 24 \mathrm{~m} / \mathrm{s}$ ). This velocity, and also the ratio $\approx 1.3$ to $C p$, is fairly similar to maximum orbital velocities observed experimentally and numerically for breaking waves in [31]. Similar findings are presented in [32], where it is also argued a similarity between the incident orbital velocity and run-up velocities on a column in breaking waves. This is an indication that our expected relation between the rise velocity and the orbital velocity is a reasonable assumption also in such high nonlinear waves. The ratio 1.3 is close to 1.2, as recommended for breaking waves by DNV GL [7], as well as to 1.35, as mentioned in [32].

As mentioned above, the exact magnitudes of the peak rise velocities in Figure 12 are somewhat sensitive to the low-pass filter used during the derivation from the original elevation record. Thereby, some uncertainty in the order of $5 \%$ should be considered regarding absolute magnitudes. However, since the same filter, with the same related uncertainty, has been used for all events, results for different events can be compared directly, and the uncertainty is therefore not crucial in the study of correlation against loads.

\subsection{Correlation of Deck Loads Against Wave Parameters and Theoretical Estimates}

One basic aim of this study was to check how well the use of the measured rise velocity, through our simple derived theoretical wave impact load models of Equations (5) and (9), compare to the measured impact loads. Ideally, an event-by-event correlation between measurement and theory would be helpful in this. However, we found that, due to significant random variability, such a direct correlation is not meaningful for the random steep wave events in steep irregular waves, and an alternative presentation approach is applied (see the paragraphs below). This large random variability in wave slamming loads is quite well known and was expected. For the regular wave tests, however, the impact loads exhibit less random variations.

\subsubsection{Regular Waves}

For regular waves, direct correlation is possible, as shown in Figure 13. Both the local slamming pressures and the global deck forces are in fact quite well correlated with their respective simple prediction models, which forms a good basis for the goodness of the wave load modelling in Section 2.2. There is a slight model overprediction of the local pressure, while the global forces are slightly underpredicted. This small difference in the local vs. global force comparison may be due to the additional global horizontal forces due to the girders. (The low matching for lowest slamming pressure measurements may be due to marginal events with only parts of the water hitting the slamming panel, together with a corresponding larger relative uncertainty in the estimation of the immersion depth $h$ in these cases. For the global force, the matching is better in these cases, probably because the total wetted height $H_{D}$ is better defined).

As shown below, contrary to the irregular wave cases, the impact in regular waves is to a large extent governed by the hydrostatic pressure, i.e., the first terms in Equations (5) and (9), which is statistically clearly more stable than the dynamic slamming loads. 

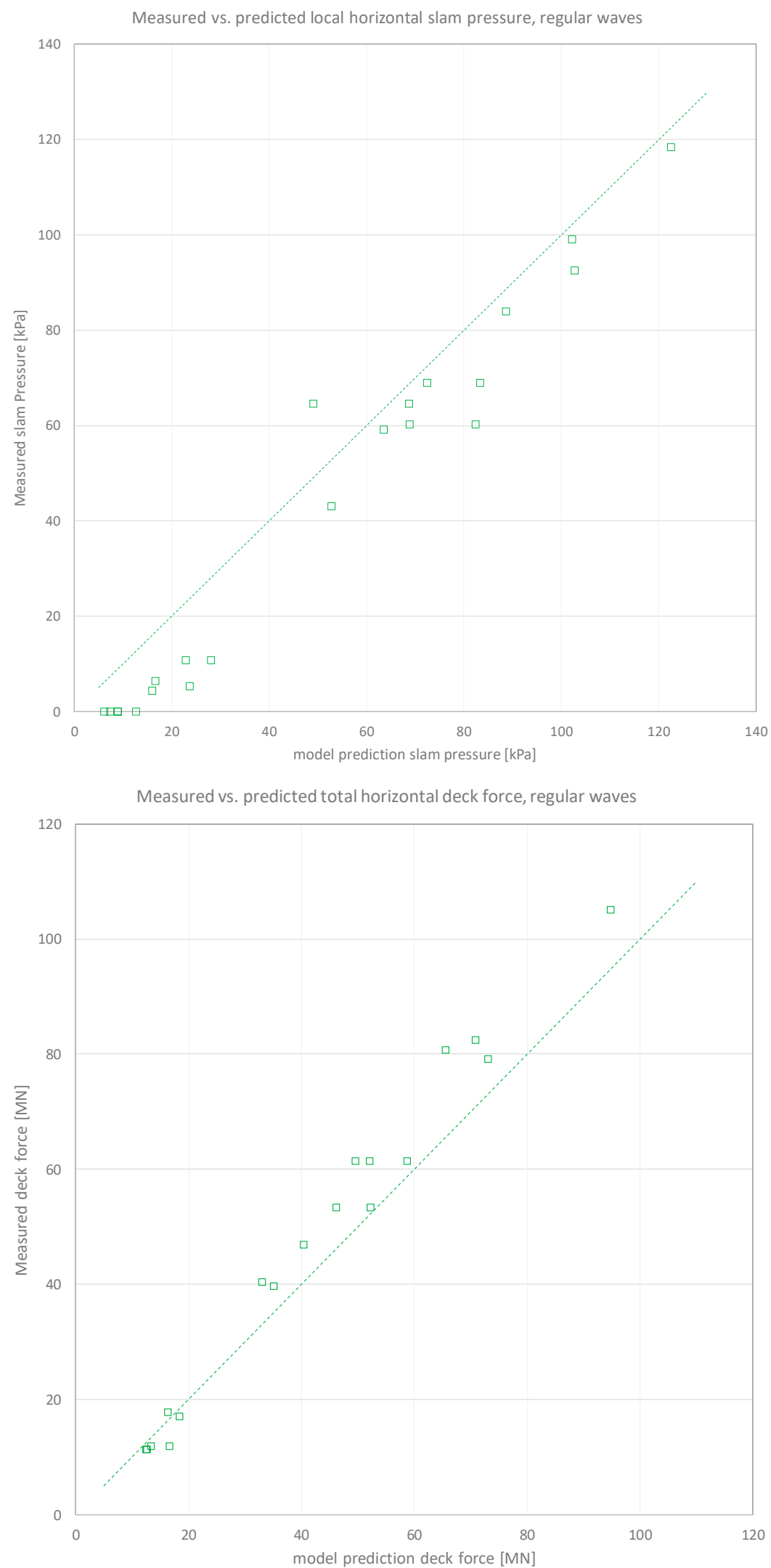

Figure 13. Correlation between measured deck impact load peaks and model predictions, regular waves: (top) local horizontal slamming pressure; and (bottom) global horizontal force. 


\subsubsection{Irregular Waves}

The main results from the irregular waves are presented in a different way in Figures 14 and 15. Here, the measured horizontal impact load peaks from the total dataset are, instead, correlated against the corresponding incident crest peaks, and at the same time compared to corresponding theoretical results based on the incident crests combined with Equations (5) and (9). This presentation approach is an extension of the simple correlation type of plot in Figure 3 and other similar plots in [8], with the aim to also highlight the influence from the peak rise velocity, i.e., local steepness combined with the near-surface orbital velocity.

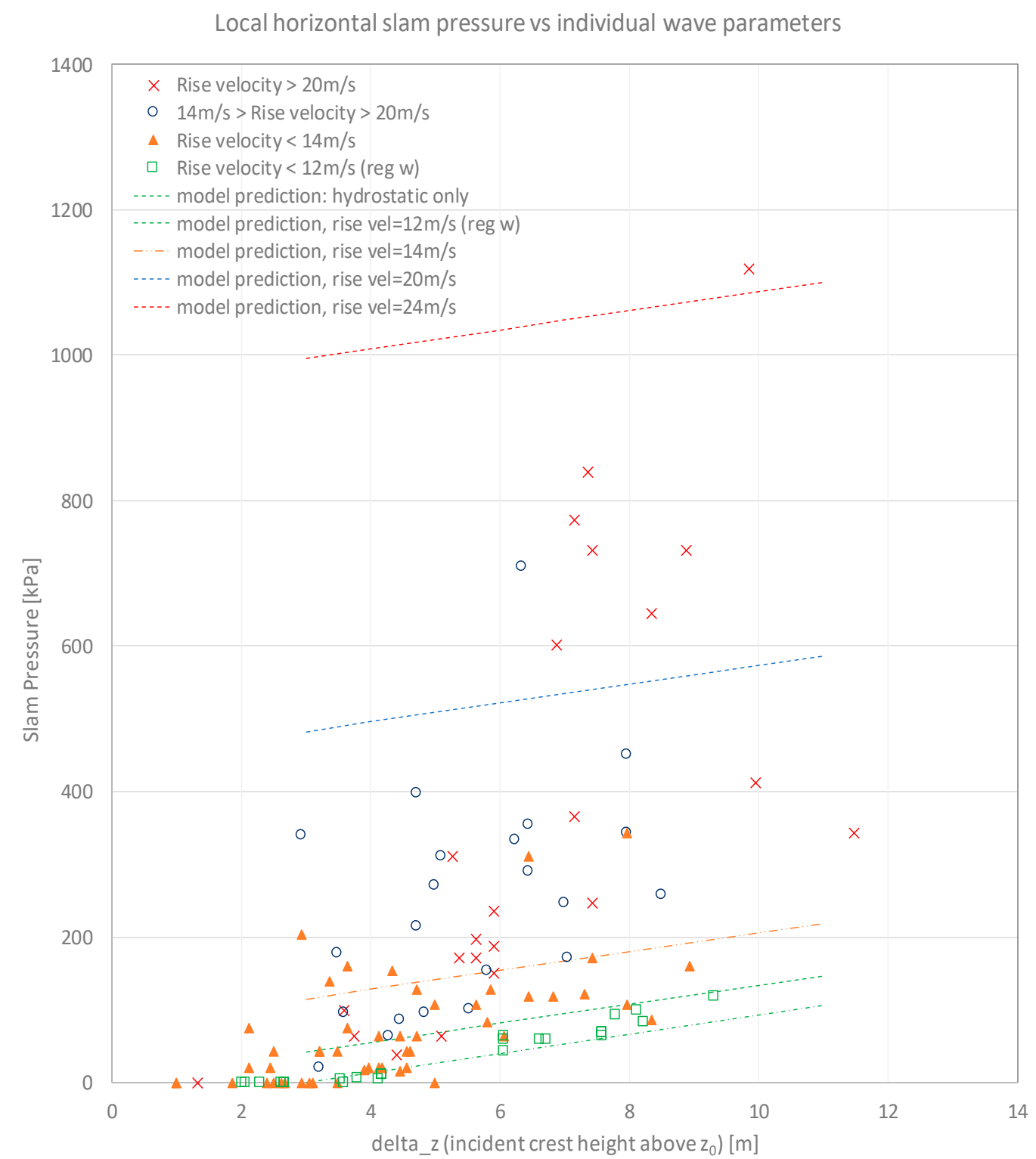

Figure 14. Correlation between measured local slamming pressure peaks and corresponding incident crest height above reference level $\mathrm{z}_{0}$. Here, $\mathrm{z}_{0}=15 \mathrm{~m}$ for water depth $151.6 \mathrm{~m}$ and $16.5 \mathrm{~m}$ for water depth $150.1 \mathrm{~m}$. Estimates from simple theoretical model Equation (5) are also indicated.

While Figure 14 shows the local slamming pressure from the $7.5-\mathrm{m}^{2}$ slamming force panel on the lower deck front, Figure 15 shows the global (integrated) deck forces. As explained and argued at the end of Section 3.2, the results in each of the two figures include data from testing in two different water depth, namely 150.1 and $151.6 \mathrm{~m}$, respectively, to obtain one larger dataset instead of two. The 
combination of data is done by defining a "zero-level" (or reference level) $z_{0}$, which is $15 \mathrm{~m}$ for the $151.6 \mathrm{~m}$ depth and $16.5 \mathrm{~m}$ for the $150.1 \mathrm{~m}$ depth (see Figure 8 ). In the theoretical predictions, we made use of estimates for the maximum depth $h$ of the slamming panel immersion and for the maximum wetted height $H_{D}$, as explained in Section 3.2.

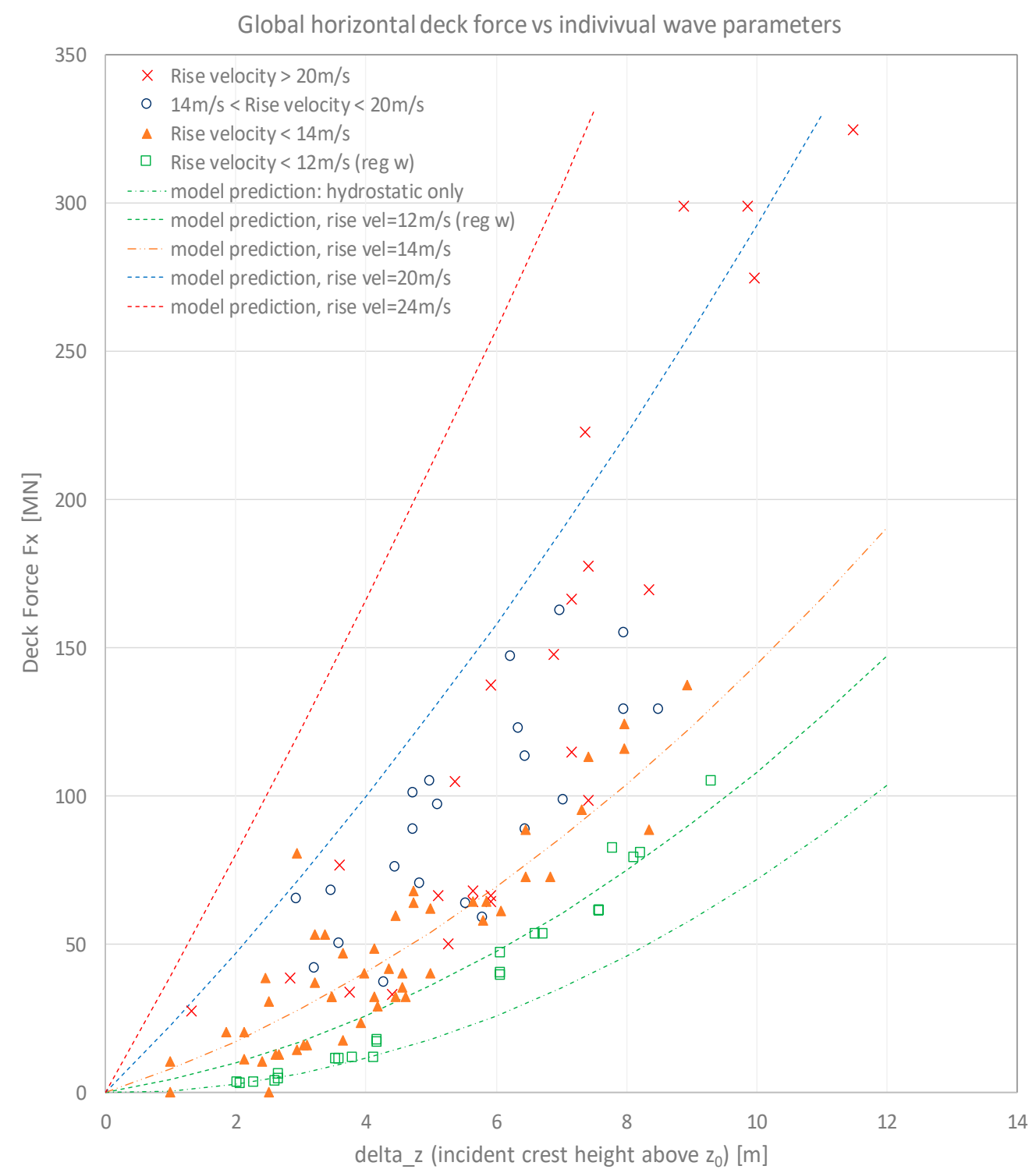

Figure 15. Correlation between measured global impact force peaks and corresponding incident crest height above reference level $\mathrm{z}_{0}$. Here, $\mathrm{z}_{0}=15 \mathrm{~m}$ for water depth $151.6 \mathrm{~m}$ and $16.5 \mathrm{~m}$ for water depth $150.1 \mathrm{~m}$. Estimates from simple theoretical model Equation (9) are also indicated.

Furthermore, for each measured impact event in Figures 14 and 15, the corresponding peak values of the rise velocity were estimated from the incident elevation signal, and thereby the data are distinguished into various "classes" of rise velocities. This is indicated by different colours and markers in the figures, as described in the following:

- Green square markers denote regular waves (with rise velocities between 7 and $12 \mathrm{~m} / \mathrm{s}$ ).

- Brown triangle markers denote irregular wave events with velocities $<14 \mathrm{~m} / \mathrm{s}$, which we found to be a reasonable level class corresponding to the lowest wave-in-deck loads in irregular waves.

- Blue circles denote events with velocities between 14 and $20 \mathrm{~m} / \mathrm{s}$, for which we found that impact loads mostly grow quite high, 
- $\quad$ Red crosses denote the events with the highest velocities, i.e., $>20 \mathrm{~m} / \mathrm{s}$ (the estimated celerity).

The same colours are used in line graphs indicating theoretical estimates relevant for the different classes, respectively: green graphs for zero velocity (i.e., hydrostatic pressure only) and $12 \mathrm{~m} / \mathrm{s}$; brown graph for $14 \mathrm{~m} / \mathrm{s}$; blue graphs for $20 \mathrm{~m} / \mathrm{s}$; and red graphs for $24 \mathrm{~m} / \mathrm{s}$.

\subsection{Discussion}

The low level of random scatter in the regular wave results means that those results are useful as a first deterministic check of our simple models. The good match in Figure 13 is a promising validation. Among others, this supports our estimation of the crest amplification and corresponding wetted height levels described in Section 3.2, and for the integrated deck force it indicates a good "calibration" of Equation (9) when used with an area defined reduction factor of 2.5 in these waves. These regular wave results are consistent with the good match observed in a previous comparison to CFD analysis of the present GBS case in [33].

For the irregular waves, although the results in Figures 14 and 15 do reflect a considerable random scatter in the results, especially in the local pressures but also somewhat in the global forces, we see a clear trend that increased rise velocities lead to increased deck impact loads. These findings are strengthened by a fairly good match to the theoretical estimates, in the following way: the observations for each "class" seem to be roughly within the limits given by the theoretical lines, with some exceptions. The trends are most clearly seen for the highest relative wave crests $\Delta z$. Thereby, the theoretical estimates can be considered roughly as upper limits of the random scatter in observed loads. The reasons most events show lower values are discussed below. In addition, we see that the scatter increases with the velocity.

The match is quite promising on the background of the simple 2D formulation based on the incident wave characteristics combined with a simple overall geometry model. The observations support our hypothesis that such a model based on the incident wave includes main underlying physical mechanisms, in a manner that is sufficient for us being able to identify critical events in this case. However, given the simplifications, the present theoretical models must be used with care in general use. It might be a helpful fast and efficient tool in early engineering stages, while more sophisticated computational tools are recommended for more detailed analysis.

Given that impact occurs, which requires that the incident crest heights $A_{w}$ are higher than about $6 \mathrm{~m}$ below the cellar deck for this platform case, the largest impact loads occur with rise velocities higher than $14 \mathrm{~m} / \mathrm{s}$, as mentioned above. Velocities in the range 7-12 m/s (regular waves) relate to the lowest loads. The plots confirm that in regular waves the hydrostatic pressure dominates, especially in the lowest load events where rise velocities $\approx 7-10 \mathrm{~m} / \mathrm{s}$. On the other hand, for the steepest irregular wave events with velocities $\approx 14-30 \mathrm{~m} / \mathrm{s}$ (blue circles and red crosses), dynamic slamming pressures clearly dominate the loads leading to local pressures up to 3-10 times, and global peaks approximately 3-4 times, the hydrostatic contribution.

We should keep in mind that the peak rise velocity is defined at the steepest point of the wave front surface. This point may not be exactly at the part of the crest that hits the deck; most likely, it is at slightly lower level in many cases, which may have two consequences: (1) the predicted loads from Equations (5) and (8) may to some extent overpredict the loads; and (2) it may increase the random variability since the steepest point will vary in space from event to event. Such underprediction and variability becomes more important the steeper and more nonlinear the wave is, since the rise velocity will then be very sensitive to the exact vertical position, and it may be most relevant for the most extreme cases with breaking waves. To the extent that we believe in the theoretical models in Equations (5) and (9), the underlying rise velocity data (not shown in all details in the correlation plots) do in fact indicate such underprediction for the highest events, especially for the global loads. This is because pressures would probably be higher at a lower position. Slamming pressures on columns (i.e., lower than the deck) in such waves have been found to be many times higher than the present levels of $\sim 0.5-1 \mathrm{MPa}[3,18,31]$. 
Regarding the global (integrated) loads, as derived from our model, most of the predicted highest global loads appear to be caused by events with rise velocities lower than $20 \mathrm{~m} / \mathrm{s}$. However, the mentioned underlying data do include several events with velocities up to $25-30 \mathrm{~m}$, such as in the time series examples in Figure 11. This can be explained by, in addition to the effect of the vertical position, the fact that the highest rise velocities and corresponding pressures are very local in both vertical and horizontal space, while the spatially averaged pressures over the total deck wall is clearly lower. There are 3D effects that disturb our 2D simplified impact picture. Our model in Equation (9) does aim at taking this into account through the reduction factor of 2.5 but is perhaps not complete enough.

3D effects are enhanced when large deck and/or substructure details disturb the water flow. The tension-leg platform (TLP) green-water CFD study presented in [12] is such a case. The hydrodynamic pressure from wave impact on a relatively small deck module showed significant spatial variations across the module wall, varying roughly from 400 to $800 \mathrm{kPa}$ in a 10,000 -year Norwegian Sea state. However, the average pressure over the module is strikingly similar to the local pressure levels observed in the present GBS tests, which indicates that the underlying physics from the incident wave may still be a governing mechanism there. One should note that the waves and the diffraction effects were somewhat higher for the TLP case than in the present GBS case, but the deck level was also clearly higher, thus the two cases may be roughly comparable.

Scaling effects in hydrodynamic impact model testing are mainly related with air entrainment and corresponding surface tension issues $[10,34,35]$. Thereby, if air is locked in cavities, measured loads in model scale can be conservative. Evidence of such effects are often seen as rapid oscillations in the measured load time series (not to be confused with dynamical sensor oscillations, which are quite small in these tests). With regard to the plunging wave-in-deck measurements in [10], air cavities seem to be related to the fact that the incident plunging breaking wave crest is clearly higher than the whole deck wall (which is a very critical condition, and may be not realistic in many design cases), in which case a cavity may be naturally formed by the plunger geometry. In the present wave-in-deck model testing, we consider that such cavity effects are smaller for horizontal loads, since: (1) the crests are only partly exceeding the cellar deck (see, e.g., Figure 7), and air leakage is likely because of the truncated deck wall height in the wetted zone; and (2) the local slamming time series details (see, e.g., Figure 2, bottom) do not exhibit much oscillations. Other possible scale effects are related with details of surface tension and viscous effects in breaking waves $[14,15,30]$, which may possibly lead to conservative forces in model scale. This needs more research.

Given the uncertainties in our model, it must be used with care. However, the present comparisons do indicate very promising agreements regarding its purpose. That is, the formulation in Section 2.2, based on the observed vertical rise velocity $\partial \eta(t) / \partial t$ in the undisturbed wave at a fixed point in space, is a reasonable approach for efficient pre-checks or screening of wave-in-deck slamming loads, at least for a fixed structure. Thereby, the formulation can also be a reasonable basis for further work on the methods for sampling of only critical random wave events for model testing (or CFD studies) in design studies of wave impact. However, for more detailed and quantitative numerical analyses, more sophisticated tools such as fully nonlinear or CFD methods should be applied.

\section{Summary with Conclusions}

The vertical elevation rise velocity $\partial \eta(t) / \partial t$ measured at a fixed location in a wave field is strongly correlated both with the near-surface orbital velocity and with the corresponding local wave slope.

In laboratory measured breaking or near-breaking random waves, the rise velocity is found to be roughly similar to, and sometimes even higher than, the phase velocity (celerity). The velocities are also similar to near-crest orbital velocities as observed in the literature for such waves.

A simple 2D analytical slamming model for expected local and global horizontal wave impact loads on a platform deck is proposed, based on the rise velocity from the incoming wave elevation record and the overall platform geometry only. Obviously, such a model has clear limitations in the accurate load estimation, and it must be used with care, but the idea is that such an efficient approach 
can be useful and practical in some engineering applications such as the identification of critical events in a long-duration wave train.

Based on data from a previous GBS wave-in-deck experiment, a reasonable correlation is observed between measured deck impact loads and the underlying wave rise velocity. There is also a significant random scatter in the results; this scatter increases with increasing velocities.

The observed impact loads also generally compare well with the simple model, in that the model seems to represent an approximate upper limit for the measured impact loads. The agreement is best for the highest loads. This compliance supports the idea that the underlying rise velocity, and thus the load formulation, can be useful in the identification of critical events in a random wave train, and thereby for establishing efficient model testing using only relevant parts of the wave history.

Funding: This research was funded by the Research Council of Norway for the grants provided under the FORINFRA Program (Large Scale Infrastructures), Phase III, grant 269870.

Acknowledgments: The experimental data were made available for this research by the owner Equinor, for which the author is grateful. Furthermore, the author is grateful to SINTEF Ocean for the invitation to work on this project.

Conflicts of Interest: The author declares no conflict of interest. The funders had no role in the design of the study; in the collection, analyses, or interpretation of data; in the writing of the manuscript, or in the decision to publish the results.

\section{References}

1. PSA. Granskingsrapport Etter Hendelse Med fatalt Utfall på COSL Innovator 30, December 2015, Report, Revised version; Petroleum Safety Authority Norway: Stavanger, Norway, 6 July 2016. (In Norwegian)

2. DNV GL OTG-13. Prediction of Air Gap for Column Stabilized Units; DNV GL Guideline: Høvik, Norway, 2019.

3. DNV GL OTG-14. Horizontal Wave Impact Loads for Column Stabilized Units; DNV GL Guideline: Høvik, Norway, 2019.

4. Kaplan, P.; Murray, J.J.; Yu, W.C. Theoretical analysis of wave impact forces on platform deck structures. In Proceedings of the 14th International Conference on Offshore Mechanics and Arctic Engineering, Copenhagen, Denmark, 18-22 June 1995.

5. RP2A-WSD, American Petroleum Institute. Recommended Practice for Planning, Designing and Constructing Fixed Offshore Platforms-Working Stress Design, 21st ed.; American Petroleum Institute: Washington, DC, USA, 2000.

6. Winterstein, S.R.; Sweetman, B. Air Gap Response of Floating Structures: Statistical Predictions vs. Observed Behavior; Paper \# OMAE 99-6042. Proceeding of the 18th International Offshore MeCHANICS \& Arctic Engineering Conference (OMAE 99), St. John's, NFL, Canada, 11-16 June 1999.

7. DNVGL-RP-C205. Environmental Conditions and Environmental Loads; DNV GL Recommended Practice: Høvik, Norway, 2019; Chapter 8.

8. Stansberg, C.T.; Baarholm, R.; Fokk, T.; Gudmestad, O.T.; Haver, S. Wave Amplification and Possible Deck Impact on a Gravity Based Structure in 10-4 Probability Extreme Crest Heights; Paper \# OMAE2004-51506. In Proceedings of the 23rd International Conference on Offshore Mechanics and Arctic Engineering (OMAE 2004), Vancouver, BC, Canada, 20-25 June 2004.

9. Scharnke, J.; Lindeboom, R.; Duz, B. Wave-in-deck loads in relation with wave kinematics. In Proceedings of the 36th International Conference on Ocean, Offshore and Arctic Engineering (OMAE2017), Trondheim, Norway, 25-30 June 2017. Paper No. OMAE2017-61406.

10. Yan, B.; Luo, M.; Bai, W. An experimental and numerical study of plunging wave impact on a box-shape structure. Mar. Struct. 2019, 66, 272-287. [CrossRef]

11. Ma, L.; Swan, C. An experimental study of wave-in-deck loading and its dependence on the properties of the incident waves. J. Fluids Struct. 2020, 92, 102784. [CrossRef]

12. Pakozdi, C.; Östman, A.; Ji, G.; Stansberg, C.T.; Reum, O.; Øvrebø, S.; Vestbøstad, T.; Sørvaag, C.; Ersland, J. Estimation of wave loads due to green water events in 10000-year conditions on a TLP deck structure. In Proceedings of the 35th International Conference on Offshore Mechanics and Arctic Engineering (OMAE 2016), Busan, Korea, 19-24 June 2016. Paper \# OMAE2016-54389. 
13. Duz, B.; Lindeboom, R.C.J.; Scharnke, J.; Helder, J.; Bandringa, H. Comparison of breaking wave kinematics form numerical simulations with PIV measurements. In Proceedings of the 36th International Conference on Offshore Mechanics and Arctic Engineering (OMAE 2017), Trondheim, Norway, 25-30 June 2017. Paper \# OMAE2017-61698.

14. Albarello, A.; Pakozdi, C.; Nelli, F.; Bitner-Gregersen, E.M. Three dimensional velocity field underneath a breaking rogue wave. In Proceedings of the 36th International Conference on Offshore Mechanics and Arctic Engineering (OMAE 2017), Trondheim, Norway, 25-30 June 2017. Paper \# OMAE2017-61237.

15. Albarello, A.; Iafrati, A. The velocity field underneath a breaking rogue wave: Laboratory experiments versus numerical simulations. Fluids 2019, 4, 68. [CrossRef]

16. Petrini, F.; Manenti, S.; Gkoumas, K.; Bontempi, F. Structural design and analysis of offshore wind turbines from a system point of view. Wind. Eng. 2010, 34, 85-108. [CrossRef]

17. Manenti, S.; Petrini, F. Dynamic Analysis of an Offshore Wind Turbine: Wind-Waves Nonlinear Interaction. In Proceedings of the 12th International Conference on Earth and Space, Honolulu, HI, USA, 14-17 March 2010; Code 81209. pp. 2014-2026.

18. Vestbøstad, T.M.; Økland, O.D.; Lian, G.; Stavang, T.P. Column Slamming Loads on a TLP From Steep and Breaking Waves. In Proceedings of the 36th International Conference on Offshore Mechanics and Arctic Engineering (OMAE 2017), Trondheim, Norway, 25-30 June 2017. Paper \# OMAE2017-61786.

19. Huang, Z.; Spencer, D.; Oberlies, R.; Watts, G.; Xiao, W. Wave Impact Experiment of a GBS Model in Large Waves. In Proceedings of the 36th International Conference on Offshore Mechanics and Arctic Engineering (OMAE 2017), Trondheim, Norway, 25-30 June 2017. Paper \# OMAE2017-61473.

20. Stansberg, C.T. A Wave Impact Parameter. In Proceedings of the 27th International Conference on Offshore Mechanics and Arctic Engineering (OMAE 2008), Estoril, Portugal, 15-20 June 2008. Paper \# OMAE2008-57801.

21. Bunnik, T.; Pakozdi, C.; Stansberg, C.T.; Fouques, S.; Somers, L. Useful Indicators for Screening of Sea States for Wave Impacts on Fixed and Floating Platforms. In Proceedings of the 37th International Conference on Offshore Mechanics and Arctic Engineering (OMAE 2018), Madrid, Spain, 17-22 June 2018. Paper \# OMAE2018-78544.

22. Bunnik, T.; Scharnke, J.; de Ridder, E.-J. Efficient indicators for screening of random waves for wave impacts on a jacket platform and a fixed offshore wind turbine. In Proceedings of the 38th International Conference on Offshore Mechanics and Arctic Engineering (OMAE 2019), Glasgow, UK, 9-14 June 2019. Paper \# OMAE2019-95481.

23. Bitner-Gregersen, E.M.; Mørk, K.; Stansberg, C.T. Extreme Wave Steepness of Second- and Third Order Model Waves. In Proceedings of the 5th International Offshore and Polar Engineering Conference, The Hague, The Netherlands, 11-16 June 1995; pp. 70-74.

24. Voogt, A.J.; Buchner, B.; Garcia, J.L.-C. Wave Impacts Excitation on Ship-Type Offshore Structures in Steep Fronted Waves. In Proceedings of the OMAE Speciality Conference on Integrity of Floating Production, Storage \& Offloading (FPSO) Systems, Houston, TX, USA, 30 August-2 September 2004.

25. Wagner, H. Über Stoß- und Gleitvorgänge an der Oberfläche von Flüssigkeiten. ZAMM 1932, 12, $193-215$. [CrossRef]

26. Faltinsen, O.M. Sea Loads on Ships and Offshore Structures; Cambridge University Press: Cambridge, UK, 1990; Chapter 9.

27. Stansberg, C.T.; Gudmestad, O.T.; Haver, S.K. Kinematics Under Extreme Waves. J. Offshore Mech. Arct. Eng. 2008, 130, 021010. [CrossRef]

28. Stansberg, C.T.; Kristiansen, T. Non-linear scattering of steep surface waves around vertical columns. Appl. Ocean Res. 2005, 27, 65-80. [CrossRef]

29. Stansberg, C.T. Nonlinear Wave Amplification around Column-Based Platforms in Steep Waves. In Proceedings of the 33rd International Conference on Offshore Mechanics and Arctic Engineering (OMAE 2014), San Francisco, CA, USA, 8-13 June 2014. Paper \# OMAE2014-24569.

30. Longuet-Higgins, M.S. Progress Toward Understanding How Waves Break. In Proceedings of the 21st Symposium on Naval Hydrodynamics, Trondheim, Norway, August 1997; The National Academies Press: Washington, DC, USA, 1997; pp. 7-28. 
31. Stansberg, C.T.; Berget, K.; Graczyk, M.; Muthanna, C.; Pakozdi, C. Breaking Wave Kinematics and Resulting Slamming Pressures on a Vertical Column. In Proceedings of the 31st International Conference on Offshore Mechanics and Arctic Engineering (OMAE 2012), Rio de Janeiro, Brazil, 1-6 June 2012. Paper No. OMAE2013-83929.

32. Roos, J.; Swan, C.; Haver, S. Wave impacts on the column of a gravity based structure. In Proceedings of the 29th International Conference on Offshore Mechanics and Arctic Engineering (OMAE 2010), Shanghai, China, 6-11 June 2010. Paper No. OMAE2010-20648.

33. Pakozdi, C.; Ostman, A.; Stansberg, C.T.; Peric, M.; Lu, H.; Baarholm, R. Estimation of Wave in Deck Load Using CFD Validated Against Model Test Data. In Proceedings of the 25th International Offshore and Polar Engineering Conference (ISOPE 2015), Kona, HI, USA, 21-26 June 2015. Paper TPC-1134.

34. Abrahamsen, B.; Faltinsen, O.M. Decay of air cavity slamming pressure oscillations during sloshing at high fillings. In Proceedings of the 24th International Workshop on Water Waves and Floating Bodies, Zelenogorsk, St Petersburg, Russia, 6 March-21 April 2009; pp. 19-22.

35. Cuomo, G.; Allsop, W.; Takahashi, S. Scaling wave impact pressures on vertical walls. Coast. Eng. 2010, 57, 604-609. [CrossRef]

(C) 2020 by the author. Licensee MDPI, Basel, Switzerland. This article is an open access article distributed under the terms and conditions of the Creative Commons Attribution (CC BY) license (http://creativecommons.org/licenses/by/4.0/). 